\title{
Who Did What to Whom in the Context of Neo-Aramaic
}

This chapter introduces the main principles of Neo-Aramaic morphosyntax and the theoretical preliminaries for subsequent chapters. The prefix and suffix conjugation so well known to Semitists that they could be taken for granted as a component of any Semitic language simply do not occur in Northeastern and Central Neo-Aramaic. Instead, a major distinction is made between clauses where verbal inflection is based on qațal- and clauses based on qțil-, the two main inflectional bases of the Neo-Aramaic verbal system. Both are reflexes of pre-modern Aramaic participles, the active and the resultative participle respectively. Apart from that, several dialects make use of compound verbal constructions based on nominal forms of the verb, notably the verbal adjective (viz. resultative participle) and the infinitive (viz. action noun). Moreover, such constructions often involve person marking through (originally) pronominal copulas much more verb-like than found in most Semitic languages. Overviews of the pronominal inventory and verbal inflection are given at the end of this chapter. Tables 8 and 9 provide examples of full paradigms of the pronouns, discussed in Section 2.2. Table 10 is a simplified overview of the inflectional categories of main verb types. Table 11 displays the template for the main forms and functions of the so-called qatal-conjugation, discussed in Section 2.1.

Since the same or similar terminology can be used differently in debates in the literature on Neo-Aramaic, an outline of the basic assumptions and methodology is required. Alignment involves much more than the case systems well known to Semitists through Akkadian and Classical Arabic. Case terminology such as accusative or ergative should not be conflated with the functions of the arguments in the clause, i.e. speaking of accusative or ergative functions should be avoided, nor with verbal person marker sets, i.e. terms like 'accusative L-suffixes' or 'ergative L-suffixes' are to be avoided, and semantic roles, i.e. agent or patient, should not be confused with syntactic functions, i.e. S, A and P, and so forth. Confusing terms like 'accusative L-suffix' or 'ergative case role' will not be used in this book. Instead more fine-grained categories of the functions of arguments in the clause structure will be used in the application of the models developed by Comrie (1989) and Andrews (2007) for alignment typology.

Moreover, ergativity should not be mistaken for a property of a particular (historically) passive-like transitive construction in which the agent is marked 
in a (historically) prepositional phrase. Rather it embodies the similar treatment of a particular set of core grammatical functions, namely $\mathrm{S}$ and $\mathrm{P}$, which could be manifested in multiple ways, case morphology being only one factor among many.

Indeed, alignment typology seeks to capture variation by comparing the way arguments are treated in core grammatical functions in the clause structure, ergative-absolutive being one among several alternatives to nominativeaccusative. In this regard, a major distinction is made between transitive and intransitive clauses depending on the number as well as functions of arguments, i.e. any of the arguments with which primary transitive verbs combine to express the main participants of the event denoted by the construction. The way such arguments are marked similarly or differently across transitive and intransitive clauses establishes particular types of groupings in which languages vary and change. Adopting a language and construction-specific typological approach to such variation will inevitably have a different theoretical basis and purpose than approaches based on universal grammar in generative syntax. ${ }^{1}$ Moreover, taking clause structure to be ultimately constructionspecific also leads to different outcomes, namely that alignment types can be identified from different perspectives by examining the morphological properties of the construction in closer detail.

\subsection{Main Components of Verbal Inflection in Neo-Aramaic}

As in other Semitic languages, the Neo-Aramaic verb is presupposed to have three primary levels of morphological abstraction, discussed further below:

1) root, mainly consisting of three radical consonants, with an associated meaning, such as

$\begin{array}{lllllll}d-m-x & q-t-l & n-\check{s}-q & g-r-s & \check{s}-q-l & s-m-q & p-l-t \\ \text { 'sleep' } & \text { 'kill' } & \text { 'kiss' } & \text { 'pull' } & \text { 'take' } & \text { 'be(come) red' } & \text { 'move out' }\end{array}$

2) derivational stem, a verbal derivation consisting of this root and possibly additional affixes/augments to distinguish verb classes and different voices such as causative and mediopassive, e.g.

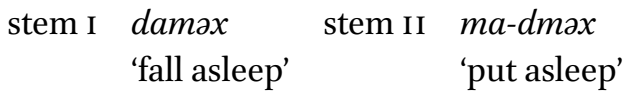

1 See, for instance, Hoberman $\left(1989,95^{-122}\right)$ for a generative morphological account, Doron and Khan (2010, 2012) and Kalin and van Urk (2015) for alignment typology from a generative syntactic perspective. 
3) inflectional base, which consists of a vowel template with slots for the radicals and selects a paradigm of verbal endings that jointly determine how the verb is conjugated and together convey a particular state of affairs, e.g. damx -әn 'I $\mathrm{MS}_{\mathrm{MS}}$ sleep' < damax- + E-suffixes

sleep -1MS

- preverbs are added to mark tense, aspect and/or mood, e.g.

$b$ - damx-ən ' $\mathrm{I}_{\mathrm{MS}}$ will sleep'

FUT- sleep-1Ms

- a past or anterior -wa-suffix denoting past tense or "one step back" (Cohen 2012, 459) in time, e.g.

b- $\quad$ damx-on $-w a \quad$ 'I $\mathrm{MS}_{\mathrm{MS}}$ used to sleep'

FUT- sleep-1MS -PST

A fully conjugated form of a verb like šm' 'hear' belonging to stem I such as $k$ šam'-á-wa-li 'She used to hear me' follows the following template:

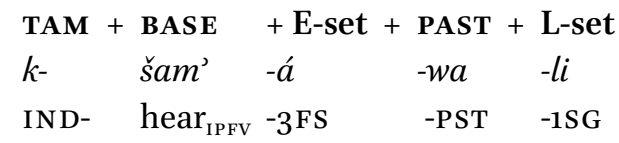

'She used to hear me.'

This basic template begins with a marker of clause-level grammatical information in which the categories of tense, aspect and mood are fused, such as the indicative-habitual $k$ - What follows such TAM-markers is a verbal stem derived from the root $s^{\prime} m$ that encodes the core meaning of the verbal construction (e.g. šame'- hear ${ }_{\mathrm{IPFV}}$ ), to which the person markers of a particular set (the Esuffixes) are added. After the E-suffix and before the L-suffix, the affix -wa- is added expressing one step back in time (i.e. anteriority). We will review each of these levels accordingly in the following sections, starting with verbal roots.

\subsubsection{Verbal Roots}

Verbal roots are generally composed of three radicals, at least one of which may be lost in the inflection of so-called weak verbs.

First of all, Neo-Aramaic languages are generally described within the traditional mold of a Semitic language that is characterized by verbal roots composed of a particular set of so-called radical consonants. While inflectional stems are still analyzable as vowel templates, it is ambiguous to what extent these roots are still productive or identifiable on the synchronic level. ${ }^{2}$ This

2 See Molin (2021) for a discussion, in particular the verb 'by 'want'. Consider, for instance, the 
notwithstanding, verbal roots are at least identifiable on a diachronic basis, and these are referred to as such in the grammatical description throughout this monograph for ease of cross-dialectal comparison.

There are mainly three - but sometimes four - radicals per verbal root, indicated as $\mathrm{C}_{1}-\mathrm{C}_{2}-\mathrm{C}_{3}$-where $\mathrm{C}$ stands for the slot taken by the respective radical consonant. The roots for 'kiss', 'pull' and 'kill', for example, are, respectively, $n$ $\check{s}-q, g-r-\check{s}$ and $q-t-l$ in Aramaic. They are generally used as 'dummy' verbs, i.e. the default descriptive example from which we can deduce how other verbs are inflected. Whereas most verbs are triradical, quite a number of them can also contain more than three radicals, being, for instance, quadriradical, such as $d-l-g-n$ 'tell a lie' and $g-n-d-r$ 'roll'.

Furthermore, the position and quality of a radical in a particular consonantvowel template that constitutes a verbal form can affect the way the verb is inflected. Semitists generally distinguish between sound verbs, which regularly retain all radicals in inflection (such as $g-r-s^{\prime}$ 'pull'), and weak verbs, which contain a radical that is somehow lost, primarily the semi-vowels $y$ and $w ;$ though usually leaving behind some trace in the phonology. ${ }^{4}$ Table 2 below represents how they are differentiated further by the position of their weakness: first, second (or hollow), and final weak verbs, respectively. ${ }^{5}$

The type of radical is usually specified. For example, $q-y-m$ 'rise' belongs to the hollow verbs, more specifically the second-/y/ verbs, $k-t-w$ to the final weak verbs, more specifically the final-/w/ and so forth. Verbal roots containing a final resonant are also subsumed under weak verbs in certain Neo-Aramaic languages. Final-/r/ verbs, for example, can constitute a special class. In principle weak verbs are as systematic or predictable as sound verbs. The fact that their triradicalism is partially or completely weakened in their inflectional system is what sets them apart. They should not to be mistaken for irregular verbs per se,

verbal forms $k$-e 'he comes' and $k$-en 'they come' in Trans-Zab Jewish varieties like J. Sanandaj (Khan 2009), where $k$ - is a тAм modifying prefix. Since the historical root 'ty 'come' is no longer identifiable at all, it is questionable whether one wants to postulate a root here at all on a synchronic level.

3 Historically, $w$ is the reflex of the spirantized allophone of /b/ in pre-modern Aramaic. The shift from ${ }^{*} \underline{b}$ to $w$ (e.g. * $k \underline{t} o \underline{b} o>$ T⿱uroyo $k \underline{t} o w o$ ) gave rise to new weak roots, such as $g-n$-w 'steal' $\left(<{ }^{*} g-n-b\right), k-\underline{-}-w$ 'write' $\left(<{ }^{*} k-t-b\right), l-w-s ̌ s ~ ' d r e s s$ ' $(<*-b-s ̌), g-w-r$ 'marry' $\left(<{ }^{*} g-b-r\right)$. The stop allophone may still be found elsewhere, compare mzabən 'He sells' (< * mzabbən-) and zowən 'He buys' (< * $z o \underline{b} a n)$, both originally formed to the root $z-b-n$.

4 Sometimes this can involve two (or more) weak radicals (i.e. doubly weak verbs).

5 These correspond with the traditional Latin terminology of verba infirmae radicalis in Semitics, and thus verba primae, mediae or tertiae infirmae (radicalis), respectively. 
TABLE 2 Major types of weak verbs

Initial, first Second, middle, hollow Third, final

$\begin{array}{llllll}\mathrm{R}_{1}=y & y-\underline{d} \text {-c 'know' } & \mathrm{R}_{2}=y & q-y-m \text { 'rise' } & \mathrm{R}_{3}=y & \check{s}-t-y \text { 'drink' } \\ \mathrm{R}_{1}=\text { ' } & \text { '- } x \text {-l 'eat' } & \mathrm{R}_{2}=w & l-w \text {-š 'wear' } & \mathrm{R}_{3}=w & k-\underline{t}-w \text { 'write' }\end{array}$

which are inflected differently from both sound and weak verbs. The verb ' $-z-l$ 'go', for instance, is often highly irregular in Neo-Aramaic languages, sometimes even showing unique verbal person markers not used with any other verb.

Thus, in a nutshell, verbal roots generally consist of three radical consonants. Regular verbs are either sound or weak. All radicals are retained in the inflection of sound verbs such as $n-\bar{s}-q$ 'kiss'. At least one radical is lost in the inflection of weak verbs such as $q-y-m$ 'rise', usually leaving a trace behind. Irregular verbs are inflected differently from both of these.

\subsubsection{Basic Stems qațəl-/qoṭol-vs. qțil-and Their Derivations}

Both the Northeastern and Central Neo-Aramaic verbal system mainly distinguish three conjugations, of which qațal- (or qoțal) and qțil- (and/or qațil- < *qațīl-) are inflectional bases for the basic verbs.

Verbal inflection mainly consists of the following bases:

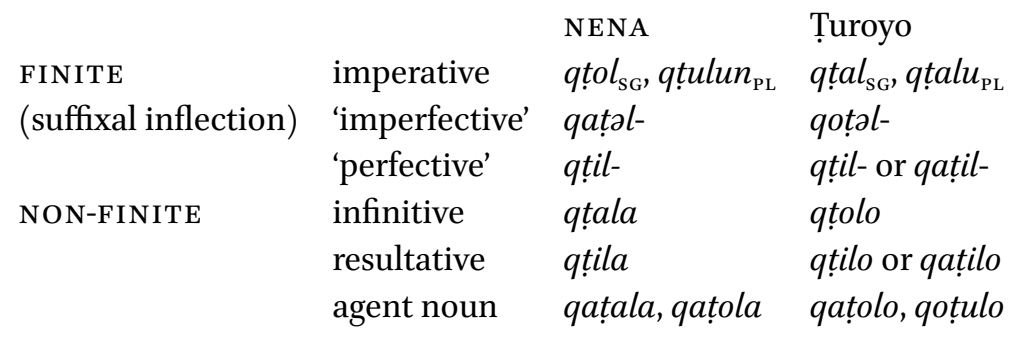

The basic verbal system primarily distinguishes three conjugations the imperative (NENA qtol, CNA qtal 'kill!'), the 'imperfective' (NENA qațal-, CNA qoțal-) and the 'perfective' (qțil-) characterized by suffixal person indexes. The Central Neo-Aramaic 'perfective' has two bases: qțil-and qațil- (< "qațtil-). Nominal forms of the verb include at least an action noun or infinitive (qtala 'killing') and verbal adjective or resultative participle ( $q$ țila 'killed'). Like the 'perfective', the latter encompasses two consonantal templates in Central Neo-Aramaic: qțilo and qațilo (< ${ }^{*}$ qatțilā). In addition, there are agent nominalizations (e.g. 
NENA ganawa 'thief', Țur. ganowo 'thief' < "gannāba $\bar{a})$ that may serve as an active participle or proximative in some varieties. ${ }^{6}$

Verbal stem formation involves several possible derivational classes. These classes are typical of Aramaic and share cognates with other Semitic languages. Semitists often distinguish a G(round) or B(asic) stem (German Grundsstamm), $\mathrm{D}$ (oubling) stem (German Doppelungsstamm) and C(ausative) stem. ${ }^{7} \mathrm{Q}$ (uadriradical) verbs usually follow the patterns of the $\mathrm{D}$-stem. Their equivalent mediopassive or reflexive counterpart are known as the 'T-stems', i.e. Gt-stem, Dt-stem, Ct-stem, Qt-stem. ${ }^{8}$ Table 3 lists such formations in Țuroyo using the imperfective base of the derivation as citation form.

In accordance with the table above, these formations are consistently referred as stems I, II, III and IV and their corresponding mediopassives as $\mathrm{I}_{\mathrm{M}}$, $\mathrm{II}_{\mathrm{M}}, \mathrm{III}_{\mathrm{M}}$ and $\mathrm{IV}_{\mathrm{M}}$. There is no common practice in Neo-Aramaic Studies to refer to these verbal derivations, but the traditional comparative Semitic terminology is not suitable for comparing Neo-Aramaic languages. ${ }^{9}$

In contrast to Central Neo-Aramaic, NENA dialects do not have mediopassive derivations. The Central Neo-Aramaic classes in Table 3 correspond with the following active forms in NENA dialects (if they are all present):

$\begin{array}{lll}\text { I: } & \text { qațal- } & \text { 'kill' } \\ \text { II: } & (m) \text { zaban- } & \text { 'sell' } \\ \text { III: } & \text { madmox- } & \text { 'put to sleep' } \\ \text { IV: } & \text { (m)barbəz- } & \text { 'scatter' }\end{array}$

Several NENA dialects only have stem III where others make a distinction between II and III. ${ }^{10}$ Notwithstanding the various derivational patterns among the stem formations within a single dialect, it is safe to say that, in general, the verbal derivations referred to as stem II and, most productively, stem III are causatives of the basic stem I, adding an agent to the valence pattern of the basic stem. The verb $d m x$, for example, means 'go to sleep' in stem I, e.g. Turoyo domax, and 'put to sleep' in stem III, e.g. Turoyo madməx.

\footnotetext{
6 See Noorlander (2017) for an overview of proximative constructions.

7 The first three are traditionally known in Aramaic Studies as (Neo-) $P^{\prime} a l,\left(\mathrm{Neo}_{-}\right) \mathrm{Pa}^{\text {ccel }}$ and (Neo-)A $\bar{p}^{-} e l$, respectively.

8 Traditionally 'Etṕal, 'Etpa“'al and 'Ettap̄'al respectively.

9 D-stem, for instance, is derived from German Doppelungsstamm 'doubling stem' due to the gemination, i.e. lengthening, of the second radical ( ${ }^{*}$ mzabban-), but gemination is no longer a characteristic of this formation in all Neo-Aramaic languages.

See also Kapeliuk (2005) for a discussion of these derivations.
} 


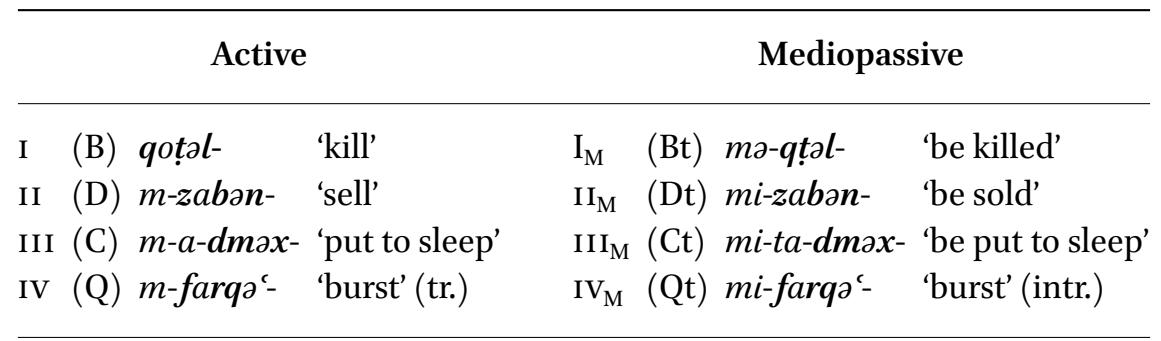

A primary distinction will be made between the two 'perfective' and 'imperfective' inflectional bases. No standard terminology exists in Neo-Aramaic Studies, but 'Present', 'Jussive', 'Subjunctive' and 'Imperfective' Base are used for qațal-and, conversely, 'Past', 'Preterit' or 'Perfective' for qțil-. Since the difference is principally inflectional in nature, a purely morphological designation is preferred here. The neutral terms qțil- and qațal-, respectively, will be used to designate these bases throughout this book. The terminology 'perfective' and 'imperfective' is functionally motivated, as qațl- is the preferred form in modal complements to express the imperfective present (i.e. subjunctive) and qtilltypically expresses the perfective past (i.e. preterit). Nevertheless, these terms should be taken loosely, since verbal forms based on qatal- can also express perfective aspect as a narrative past (e.g. Christian Barwar, Khan 2008a, 570), and qțil- can also express imperfective aspect when denoting a continuous result state in the present (Kapeliuk 2015) or proximative (Noorlander 2017), e.g. C. Barwar (Khan 2008a, 615)

$\begin{array}{llll}\text { hadiya } & \text { di } & \text {-li } & \text { 'ana } \\ \text { now know } & \text {-1SG } & \text { I } \\ \text { 'Now I know.' } & & \end{array}$

mit -le

know $_{\mathrm{PFV}}$-1SG

'He is about to die.'

These inflectional bases are the direct reflexes of the active and resultative ${ }^{11}$ participial predicates in pre-modern Aramaic. The verbal predication is traced

11 This is generally known as a passive participle in traditional Semitics. Since this form is in usage typologically closer to resultative constructions (Nedjalkov 1988, 2001), resultative participle will be used instead, especially in order to avoid cumbersome descriptions of 
back to the historically short, indefinite form. The longer, historically definite, counterpart continues as a verbal adjective termed resultative participle here, elsewhere sometimes called 'stative participle'. This resultative participle is derived from the originally definite form of the pre-modern resultative participle ('qțilā 'killed' > Țuroyo qțilo NENA qțila 'killed'). It properly joined in the levelling of the original distinction in determination between so-called absolute ('malk- $\varnothing$ 'a king') and emphatic/determined state ('malkā 'the king'). The absolute state was the default, short form of adjectives and participles in predication (" qatal- $\varnothing$ 'He kills'), which have become completely verbal in Northeastern and Central Neo-Aramaic. The longer, definite form, the emphatic state, became the regular expression of nouns and adjectives throughout. Although the resultative participle derived from the longer form typically expresses result states from an implicit prior action, ${ }^{12}$ it has in some cases undergone grammaticalization to a perfect (i.e. anterior/retrospective aspect) or even a full-fledged preterit in several NENA dialects. The term 'resultative participle', therefore, is maintained here purely for comparative purposes.

\subsubsection{Sets of Person Markers: E-suffixes and L-suffixes}

(1) Sets of person markers

\begin{tabular}{|c|c|c|c|c|}
\hline & Ṭuroyo & & $\begin{array}{l}\text { NENA } \\
\text { (J.'Amedia }\end{array}$ & ; Greenblatt 2011, 88, 91) \\
\hline & SET 1 & SET 2 & SET 1 & SET 2 \\
\hline & E-SERIES & L-SERIES & E-SERIES & L-SERIES \\
\hline $1 \mathrm{MS}$ & $-n o$ & $-l i$ & -na, -ena & $-l i$ \\
\hline $1 \mathrm{FS}$ & -ono & & $-a n,-a n a$ & \\
\hline 1PL & $-i n a$ & -lan & $-a x,-a x n i$ & -lan,-leni \\
\hline $2 \mathrm{MS}$ & $-\partial t,-a t$ & $-l \breve{u} x,-l o x$ & $-\partial t$ & $-\operatorname{lux}$ \\
\hline $2 \mathrm{FS}$ & $-a t$ & $-\operatorname{lax},-\operatorname{lax}$ & $-a t$ & $-\operatorname{lax}$ \\
\hline $2 \mathrm{PL}$ & $-u t u,-i t u$ & $-l x u$ & -etun & -loxun \\
\hline $3 \mathrm{MS}$ & $-\varnothing$ & $-l e$ & $-\varnothing$ & $-l e$ \\
\hline $3 \mathrm{FS}$ & $-O$ & $-l a$ & $-a$ & $-l a$ \\
\hline $3^{\mathrm{PL}}$ & $-i,-\partial n^{13}$ & -lle, -lan & $-i$ & -lu, -lohun \\
\hline
\end{tabular}

Two main sets of person markers are distinguished in verbal constructions, one of which goes back to enclitic personal pronouns and the other to prepositional

"active passive participles", i.e. passive in form, but active in meaning (Noorlander forthcoming).

12 See Kapeliuk (2008) for a discussion; cf. Noorlander (forthcoming).

13 Final-y verbs, e.g. 'hoz-ən 'They see'. 
pronouns. The distinct usage of these sets with qtill- is pertinent to the discussion in the following chapters. They form the basis for diverse verbal person marking alignment patterns.

Set 1 consists of the 'E-suffixes' and Set 2 of the 'L-suffixes.'. 14 The sets are illustrated in (1) above for Tuoryo (Central Neo-Aramaic) and J. 'Amedia (NENA).

Thus, E-suffixes and L-suffixes are the main sets of verbal person markers. Set 1, the E-suffixes - where E stands for enclitic due to their origin as enclitic pendants of independent pronouns ${ }^{15}$ - , can be decomposed into gender and number coding (m. $-\varnothing$, f. $-a$ and pl. $-i$ ) and person and number coding (2sg. -et, 2pl. -tun, 1sg. -no, 1pl. -na). Arguably, the first and second E-suffixes are morphologically slightly more complex than the third person, which lack special person morphemes, e.g. 3 fs. domx-o 'She sleeps' and domx-i 'They sleep'. Similarly, we can observe, to some extent, the prepositional origin of the L-suffixes, which can be decomposed into the characteristic $l$ - and an additional possessive suffix, e.g. $-l-i=l-+1$ sg. $-i,-l-a n=l-+1$ pl. $-a n$ like $b a b-i$ 'my father', $b a b$-an 'our father' etc. This will not be done here, unless there is a clear warrant to do so; for example, for closer analysis or comparative purposes. Moreover, the L-suffixes and possessive suffixes are not morphologically identical in every relevant language (see § 3.1.2.2. and § 4.1.1.3). In Jewish Saqqiz, for example, 3fs. possessive suffix is - $a v$ while the corresponding L-suffix is -la (Israeli 1998).

The terms S-suffix (in Khan's early works and similar works by other authors such as Coghill 2016) and $a$-suffix in Sinha (2001) instead of E-suffixes are unhelpful, because the S-suffixes may be confounded with the grammatical function 'subject' often abbreviated to $s$ in linguistics (which they need not express at all). E-set and L-set are meant as purely neutral morphological designations for comparative purposes without the precarious implications of any systematic relationship to the grammatical functions. Because of parallelism with Iranian, one also finds 'direct' for E-suffixes ${ }^{16}$ and 'oblique' for L-suffixes, ${ }^{17}$ which is a common practice of referring to argument marking in Iranian studies. These will not be used here either, because they may be confused with direct vs. oblique arguments, while the L-suffixes are verbal person markers and do not express an oblique argument. Finally, Jastrow $(1985,120)$ introduced

\footnotetext{
14 For this choice of terminology, cf. Mutzafi (2004a, 2008a) and Fassberg (2010).

15 Synchronically, the E-suffixes are not enclitics and should not be confused for the separate set called the enclitic copula discussed in § 2.2.4.

16 Cf. 'D-suffixes' for 'direct suffixes' in more recent work by Khan, e.g. Khan (2017).

17 Cf. Ritter (1990), Pennacchetti (1994), Murre-van den Berg (1999), Mengozzi (2002b, 2005), Noorlander (2017).
} 
"ergative Flexion" for the L-set against "prädikative Flexion" for the E-set in describing Țuroyo and Mlahsó. As these terms are already connected with a type of alignment (i.e. ergative $)^{18}$ or a type of syntactic function of parts of speech (i.e. predicative), they may lead to confusion and are therefore avoided altogether.

(2) Paradigm of qațal-for grš 'pull'

Țuroyo (Miden, SE Turkey, NENA (J. 'Amedia, NW Iraq;

cf. Jastrow 1985; Ritter 199o) Hoberman 1989; Greenblatt 2011)

1MS -no 'goraš-no -әn, -ena garš-ən, ’garš-ena

IFS -ono oŭršsono -an $(a) \quad$ garš-an $(a)$

$1 \mathrm{PL} \quad$-ina öŭrš-ina -ax(ni) ogarš-ax(ni)

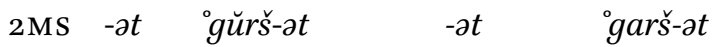

2FS -at oŭrš-at -at ogarš-at

$2 \mathrm{PL}-$-utu öŭrš-utu -etun garš-etun

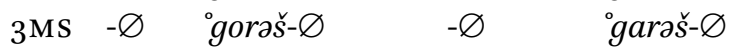

$3 \mathrm{FS} \quad-0 \quad$ gŭrš̀-o $\quad-a \quad$ garš- $a$

$3 \mathrm{PL}-i \quad$ ogŭršs $-i \quad-i \quad$ garšs $-i$

(3) Paradigm of $q t \underline{\text { ill }}$ - for grš 'pull'

Țuroyo (Miden, SE Turkey, NENA (J. 'Amedia, NW Iraq;

cf. Jastrow 1985)

based on Greenblatt 2011)

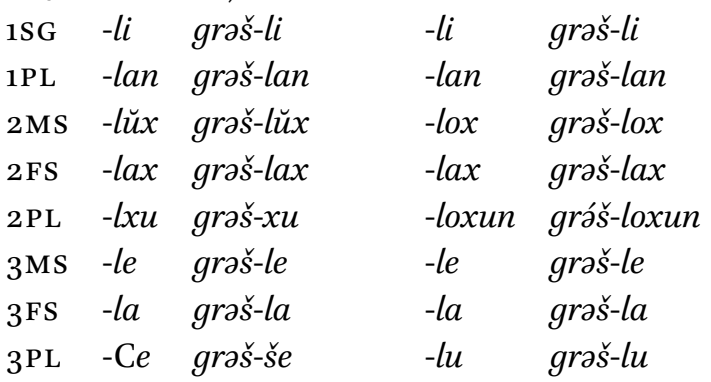

Examples (2) and (3) above illustrate the paradigms for qațal- and qțil-, respectively, in the Midən dialect of Turoyo and Jewish 'Amedia dialect of NENA. The qatal-base loses the vowel a [1] before suffixes beginning with a vowel, yielding qațl- in NENA. Due to vowel reduction, this yields qŭțl- < * qoțl- in Țuroyo and, through partial merger of /ŭ/ with /ə/, also qațl- in rural Ṭuroyo dialects.

18 Jastrow $\left(1996,5^{2-53}\right)$ himself believes that no ergative inflection is found in Neo-Aramaic languages; he adopted the term for practical reasons. 
The inflection of the qțil-base allows for considerable variation across dialects. In one respect, however, all dialects behave alike: the 2nd series (Lset) regularly expresses A in the perfective past, i.e. the preterit. The L-suffixes attach to the inflectional base qțil-, often with reduction on the part of the $i[\mathrm{i}]$ to $a[\mathrm{I}]$ or $[\mathrm{i}] \sim[\mathrm{u}]$, depending on dialect and/or phonetic context.

\subsubsection{Preverbal TAM-marking and the -wa-affix}

The verbal conjugation of qatal- primarily consists of a specific template that serves as the basis of several TAM distinctions. ${ }^{19}$ This is illustrated in (4) below. These distinctions are considerably complex and dialect-dependent. Table 11 at the end of this chapter offers a simplified overview.

\section{(4) Pattern of qațal-}

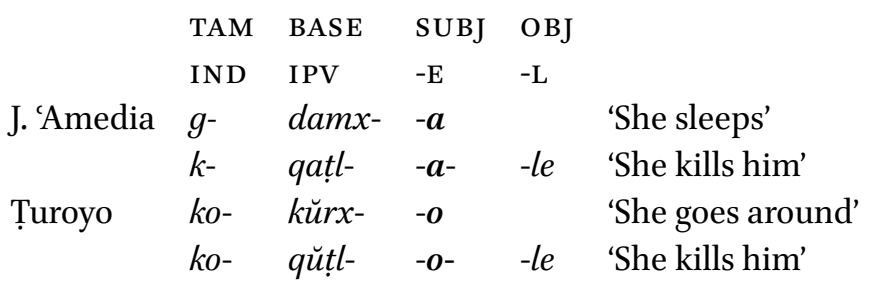

This basic template begins with a marker of clause-level grammatical information in which the categories of tense, aspect and mood are fused. The characteristically velar preverbal element $\left(k(o)-, k / g^{-}, k i-\right)$ or the (semi-)vowel $i-$ $\mid y$ - encodes the indicative habitual and/or progressive. Other TAM-markers in NENA are, for example, the prefix $b d$-, which generally encodes the future, and $q a m-$, which is marked for the transitive perfective past. The preverb $k$ - may change to $g$ - in NENA under certain (phonetic) conditions, while in Țuroyo the preverb $g$-is also a reduced variant of the future prefix $g a d$-. When preverbal TAM-markers are found for the indicative in a given dialect, the absence of preverb (i.e. $\varnothing$-) is grammatically significant in expressing a modality. It may by itself express cohortative and expresses the subjunctive form used in modal complements, for example Țuroyo

19 Some preverbal TAM-encoding is also found for other inflectional bases; see Section 3.4. for a comparison in Trans-Zab Jewish dialects of NENA, Subsection 4.1.2.2. in other NENA dialects and §5.3.3. in Neo-Aramaic dialects of Țur 'Abdin. 
$\begin{array}{lll}k-\quad \breve{u} x l & -i n a \\ \text { IND } & \text { eat } & \\ \text { IPFV } & -1 P L\end{array}$

'We are eating.'

$\varnothing-\quad \breve{u} x l \quad-i n a$

SBJV eat IPFV $-1 \mathrm{PL}$

'Let us eat!'

k-ŭb'o $\quad \varnothing-\breve{u} x l-o \quad$ 'af-farxe

IND-want $_{\text {IPFV }}-3$ FS SBJV-eat ${ }_{\text {IPFV }}-3$ Fs the-birds

'It $t_{\mathrm{F}}$ (i.e. a snake) wants to eat the birds.' (Ritter 1967-1971, 115/259)

Furthermore, the additional and set, the L-suffixes, may be added to transitive verbal forms as object suffixes, e.g. NENA ğŭrš-a-le or Țuroyo ̊̊̆ŭrš-o-le 'She pulls him'. The L-suffixes usually freely assimilate to an immediately preceding resonant, often with compensatory lengthening, e.g. NENA /b-garš-ən-lax/ ' $\mathrm{I}_{M}$ will pull you ${ }_{\mathrm{FS}}$ ' yields $b$-garš-ən-nax, and frequently also after the second person E-suffixes ending in /t/, e.g. / $\mathrm{k}$-xaz-ət-li/ yields $k$-xaz-ət- $t i{ }^{\prime}{ }^{\prime} Y_{\mathrm{MS}}$ see me'.

Relative anteriority and past tense may be further marked by the suffix $-w a,{ }^{20}$ which is added immediately after the E-suffixes, but before these L-suffixes, e.g. TTuroyo k-ŭxl-ó-wa-le 'She used to eat it $\mathrm{i}_{\mathrm{M}}$ '. Nevertheless, in some Turoyo dialects the past convertor shifts to -way- before L-suffixes and is added for the first persons before the element of the E-suffix beginning with a consonant, e.g. ko-damx-ono ' $\mathrm{I}_{\mathrm{F}}$ sleep' but damx-ó-way-no ' $\mathrm{I}_{\mathrm{F}}$ used to sleep'. The affix -wa is generally referred to as a 'past convertor' in Neo-Aramaic Studies, because the qațal-base is called the 'Present base' and its addition converts it to the past tense. Since what applies to the forms without -wa generally also applies to those with it, I will not refer to the constructions containing -wa in describing the morphosyntactic alignment, unless there are notable differences.

TAM-marking is by no means uniform across dialects. ${ }^{21}$ The indicative marker, for example, is not always compatible with the anterior, i.e. 'past convertor', -wa-suffix. Typically, the future form cannot be negated in NENA dialects found in Iraq; instead the negative indicative conveys both present and future tense, e.g. J. Dohok la-g-ezel- $\varnothing$ 'He does not go' or 'He will not go'. The distinction between the indicative marker and non-indicative zero is absent or

20 This is historically, *hwa - $\varnothing$ 'He/it was', the 3ms. suffix conjugation of the verb hwy 'be' denoting the past.

21 See Khan $(2007$ d) for an overview. 
marginalized to initial weak verbs in several NENA dialects. ${ }^{22}$ The indicative preverb $y$-can even become fused with the inflectional base of originally initial weak verbs and give rise to a new stem formation. Whereas C. Barwar (NW Iraq) contrasts indicative $i$-, e.g. $y$-axal- $\varnothing$ 'He eats', subjunctive $\varnothing$-, e.g. $\varnothing$-axal- $\varnothing$ 'He may eat', future $b$-, e.g. bt-axal- $\varnothing$ 'He will eat', the original indicative became the basis for the both indicative and subjunctive imperfective base of original initial / / verbs in C. Marga (SE Turkey): yaxəl- $\varnothing$ 'He eats/He may eat', to which the future preverb $b$-, for instance, can be added, yielding $b$-yaxal- $\varnothing$ FUT-eat ${ }_{\text {IPFV }^{-}}$ 3 Ms 'He will eat'.

Consequently, a ring symbol $\left\langle^{\circ}\right\rangle$ will be used to refer to qațal-forms without specifying its preverbal TAM-marking, but reminding the reader that such forms might be incomplete in this dialect; the present tense will be used for translation for convenience sake. A form like 'damxa 'She sleeps' thus represents all other possible forms with a preverb in the relevant dialect ranging from 'i-damxa 'She sleeps, is sleeping' (present indicative), b-damxa 'She will sleep' (future), $\varnothing$-damxa '(that) she may sleep' (subjunctive), if such forms exist in the dialect.

Thus, while TAM-marking is preverbal without affecting the order of person markers, the E-set generally precedes the -wa-affix and always precedes the Lset.

2.2

(Pro)nominals and Verbal Constructions Derived from (Pro)nominals

The nominals and independent pronouns, examines further below, represent the full expression of arguments in a clause. Unlike Western and pre-modern Aramaic, the Eastern Neo-Aramaic varieties generally no longer make a distinction between three noun states, respectively known as the absolute, construct and emphatic state in the literature. What historically corresponds with the emphatic state represented by a longer, determined nominal form, e.g. * malk- $\bar{a}$ 'the king', * malk-tāa 'the queen', is the basis of all nominal and adjectival inflection, while the historically absolute state represented by a shorter, undetermined form, e.g. * malk- $\varnothing$ '(a) king', * malk-ā'(a) queen', used in predication, e.g. *malkā țāb- $\varnothing$ 'The king is good', is the basis of all verbal inflection. The construct state has been largely replaced by constructions based on the linker $d$ (Gutman 2018). 
Like Semitic languages in general, Neo-Aramaic distinguishes between dependent and independent pronouns, i.e. person markers, respectively. Dependent person markers are attached to a verbal or non-verbal host through affixation (or cliticization) in contrast to their independent counterparts. All dependent person markers follow their host as suffixes (or enclitics) in Eastern Neo-Aramaic. ${ }^{23}$ Nouns and prepositional pronouns are inflected through a set of suffixal indexes that attach to non-verbal hosts, traditionally termed 'possessive' or pronominal suffixes. The L-suffixes can also be added to a nonverbal host, namely the existential marker, to express predicative possession. Neo-Aramaic varieties also have sets of often enclitic post-predicate copulas with a pronominal basis ${ }^{24}$ but closely interacting with the verb hwy 'be' in the predication of non-verbal elements. Originally nominal forms of the verb such as the verbal adjective (qțila 'killed') and infinitive (qtala 'killing') can occur in most of these constructions and have grammaticalized into new, compound verbal constructions.

\subsubsection{Nominal Inflection}

\subsubsection{Gender and Number}

Nouns are generally declined according to number (singular or plural) and gender (masculine or feminine), as illustrated below for Țuroyo and J. 'Amedia representing Central and Northeastern Neo-Aramaic, respectively. ${ }^{25}$ Nouns are sometimes also inflected for adnominal possession (see below) and definiteness. Prefixal definite articles occur at least in Central Neo-Aramaic, e.g. $u$-hmoro 'the ass', and some NENA dialects may have similar determiners.

\subsubsection{Pronominal Suffixes}

Pronominal suffixes typically indicate possessor complements of noun phrases (e.g. bab-i 'my father') as well as the complement of prepositional phrases. Their forms are considerably diverse both in Neo-Aramaic at large and within dialect groups. Table 6 below displays illustrative examples.

The two primary prepositions $l$ - 'to, for; on' and $b$ - 'in, at; with; through' that consist of only a single consonant are generally considered prefixal. Prefixal

\footnotetext{
23 See the previous section for the verbal person markers. This is a major morphological typological difference between Eastern Neo-Aramaic and its Western Neo-Aramaic kin (e.g. Arnold 199o) as well as its Semitic relatives, where prefixal person markers do occur.

24 Post-predicate copulas are an areal phenomenon (Haig 2001, 2014) and the pronominal basis is shared with Mesopotamian qaltu-Arabic varieties (Retsö 1987). In some NENA varieties especially in NW Iraq, however, the copula typically precedes the predicate.

25 What other languages mark through case declension is expressed through prepositions in Aramaic (see § 2.3.2.1).
} 
TABLE 4 Declension of nouns and adjectives in Țuroyo (Midyat)

\begin{tabular}{|c|c|c|c|c|}
\hline & ḥmor- 'ass' & ḩmar- 'jenny ass' & ḩวwor- 'white' & \\
\hline & MASCULINE & FEMININE & MASCULINE & FEMININE \\
\hline SG & ḩmor-o & ḩmar-to & ḩวwor-o & həwar-to \\
\hline PL & ḩmor-e & hmmar-yoto & hawor-e & hawor-e \\
\hline
\end{tabular}

TABLE 5 Declension of nouns and adjectives in NENA (J. 'Amedia)

\begin{tabular}{lllll}
\hline & xmar- 'ass' & xmar- 'jenny ass' & xwar- 'white' & \\
& MASCULINE & FEMININE & MASCULINE & FEMININE \\
SG & xmar- $a$ & xmar-ta & xwar- $a$ & xwar-ta \\
PL & xmar-e & xmar-yata & xwar-e & xwar-e \\
\hline
\end{tabular}

TABLE 6 Inflection of nouns and prepositions in Neo-Aramaic

Ṭuroyo (Miden, SE Turkey)

baba $\quad l-\quad b$ -

'father' 'to' 'in; at'

1SG $\quad b a b-i \quad$ el-i $\quad e b-i$

PL bab-an el-an eb-an

$2 \mathrm{MS} \quad b a b-\breve{u} x \quad e l-\breve{u} x \quad e b-\breve{u} x$

FS $\quad b a b-a x \quad e l-a x \quad e b-a x$

PL bab-ayxu al-xu ap-xu

3Ms bab-e el-e eb-e

FS $\quad b a b-a \quad e l-a \quad e b-a$

PL bab-ayye al-le ap-pe
NENA (J. 'Amedia, NW Iraq)

baba $\quad$ - $\quad b$ -

'father' 'to' 'in; at'

$b a b-i \quad$ วll-i ’abb-i

bab-an 'all-an 'abb-an

$b a b-o x \quad$ 'all-ox 'abb-ox

$b a b-a x \quad$ 'all-ax ’abb-ax

bab-oxun 'all-oxun 'abb-oxun

bab-e ’all-e ’abb-e

$b a b-a$ 'oll-a 'abb-a

bab-ohun 'all-ohun sabb-ohun

prepositions can be augmented with an inserted vowel in consonantal clusters either after the preposition or before it, giving rise to allomorphs like ’al- and ' $a b$ - in varieties of NENA and $e l$ - and $e b$ - in for example Turoyo. These prepositions are referred to with their allomorph in parenthesis, e.g. ('al)l- or $(e) l-.^{26}$

26 Historical *l- 'to, for' and * 'al- 'upon' merged in 'al- in most NENA dialects. The initial /ə/ 
The reduplicated allomorph lal-and dialectal variants thereof is found in some NENA dialects exclusively for pronouns.

There are intransitive verbs that specifically take a prepositional complement, such as ('al)l- or ('ab) $b$, in all Neo-Aramaic languages. The preposition is not always fixed, even within a single dialect. In J. Zakho, for example, a verb can variably combine with another preposition, compare (1a-b) below, without a noticeable semantic difference. Such complements can convey a less affected object, i.e. a target, goal or source.

(1) J. Zakho (NW Iraq; Cohen 2012, 159-16o)

a. r’วš-la ’all-a ’astāz- $a$

feel $_{\mathrm{PFV}}-\mathrm{S}: 3 \mathrm{FS}$ to-3FS master-her

'Her master noticed her.'

b. r’əš-le ’abb-i

feel $\mathrm{PFv}_{\mathrm{PF}} \mathrm{S}: 3 \mathrm{MS}$ at-1SG

'He noticed me.'

Similarly, the recipient or addressee of ditransitive verbs will generally be marked through prepositions. The addressee of the verb ' $m r$ 'say, tell', for example, is typically prepositional in Aramaic, for example:

(2) Ṭuroyo (Miden, SE Turkey; Ritter 1967-1971, 81/16)

'át-tarone mar-re l-ú-malko

the-doorkeepers say $_{\mathrm{PFv}}{ }^{-\mathrm{A}: 3 \mathrm{PL}}$ DAT-the-king:MS

'The doorkeepers said to the king.'

(3) C. Ashitha (SE Turkey; Borghero 2006, 372)

mar-ri 'all-a

say $_{\text {PFV }}$-A:1SG DAT-3FS

'I told her.'

The respective preposition that marks such recipients will vary significantly across as well as within dialects, including

could have arisen through an originally prosthetic vowel (e.g. *al-malkā for /l-malkā/), unless the -Vl-bases represent a homonymous preposition that goes back to *'el(ay)'to(ward)', which was lost in Syriac, but survived in other Aramaic languages (Jastrow 1903, $66 a)$. 

('al)l-
e.g. C. Ashitha (SE Turkey; Borghero 2006, 372)
('วb) $b-$, biy $y-27$
C. Lewen (SE Turkey; Talay 20o9, 112.37).
$t(l) a-$
C. Jilu (SE Turkey; Fox 1997, 47)
ta- $($ tal- $\sim$ tat- $)$
J. Dohok (NW Iraq; Molin 2021)
$b a(q)-$
J. Arbel (NE Iraq; Khan 1999, 119)
$q a(d / t)-$
C. Sardarid (NW Iran; Younansardaroud 2001)

\subsubsection{Unmarked vs. Prepositional Pronouns}

There is an independent set of unmarked pronouns that functions similarly to nouns, but neither inflects nor takes prepositions, alongside demonstrative pronouns.

The third person pronouns are part of a larger system of demonstratives, for example J. 'Amedia (NW Iraq; Greenblatt 2011, 83)

\begin{tabular}{|c|c|c|c|}
\hline $\begin{array}{l}\text { PROXIMAL } \\
\text { 'avya }\end{array}$ & $\begin{array}{l}\text { MEDIAL } \\
\text { 'ăwaha }\end{array}$ & $\begin{array}{l}\text { DISTAL } \\
\text { 'ăwa'ha }\end{array}$ & $\begin{array}{l}\text { ABSENT } \\
\text { ’o }\end{array}$ \\
\hline 'ayya & 'ăyaha & 'ăya'ha & 'e \\
\hline 'anna & 'ănaha & ’ăna'ha & 'an \\
\hline
\end{tabular}

All demonstratives as such can serve as third person pronouns. These demonstratives can also be prepositional, e.g. NE NA al- $d$-ö 'to that one, to him' (J. Urmi, NW Iran; Khan 2008b, 193), Turoyo l-āwo 'to that one, to him'.

The forms of independent personal pronouns differ considerably across dialects. An illustrative paradigm can be found in Tables 8 and 9 at the end of this chapter. If gender distinction occurs, independent personal pronouns are distinguished by gender only in the third person singular and sometimes also the second person singular, but never in the plural, e.g. C. Marga (SE Turkey)

$\begin{array}{llll} & \text { THIRD } & \text { SECOND } & \text { FIRST } \\ \text { ms. 'awa } & \text { 'ayat } & \text { 'ana } \\ \text { fs. 'aya } & \text { 'ayat } & \text { 'ana } \\ \text { pl. } & \text { 'ani } & \text { 'axnuton } & \text { 'axni }\end{array}$

Unlike nouns, this series of independent person markers generally does not complement prepositions ${ }^{28}$ and is thus morphologically unmarked for case, i.e.

27 For example in C. Lewen (SE Turkey; Talay 2009, 112.37).

28 The exception being the Turoyo dialect of Midyat, where personal pronouns parallel demonstratives, see Chapter 5 . 
non-prepositional. ${ }^{29}$ They are used to express a discourse-salient pronominal argument with little or no integration in the clause and are often combined with focus markers, e.g. Țuroyo óno-ste, NENA 'ána-ži 'Even, also I / me too' ${ }^{30}$

Since the unmarked personal pronouns generally cannot complement prepositions, speakers resort to the inflection of prepositions themselves through pronominal suffixes, thus respectively Țuroyo (rural) éli-ste, NENA 'alliži 'Even, to I / me too'.

There are apparent parallels between independent person markers based on the preposition $l$ - and the verbal L-suffixes. They are not always clearly distinguishable. The two are diachronically related and share certain functional properties that are sometimes even overlapping or complementary so that prepositional pronouns can be become dependent and treated like verbal person markers such as the L-suffixes. ${ }^{31}$ The L-suffixes are also analyzable as consisting of $l$ - with attached possessive suffixes, e.g. 1sg. -l-i, 1pl. -l-an. Moreover, dialects can also have a set of ' $\mathrm{B}$-suffixes' corresponding at least historically to the preposition $b-.32$

Nevertheless, the L-suffixes have a grammatical status distinct from independent prepositional pronouns and should not be understood synchronically as prepositional. All else being equal, the L-suffixes are fully grammaticalized verbal person markers and are properly an integrated part of the verbal form itself, functionally equivalent to the E-suffixes. The independent prepositional pronouns, by contrast, are equivalent to the unmarked independent set, being used more like full nominals. ${ }^{33}$

\subsubsection{Possession}

Possession can be expressed adnominally (attached to the possessee) or predicatively (independent of the possessee). Generally, an annexing particle $d$ links two nominals in adnominal possession and may be inflected for person. ${ }^{34}$ The set of L-suffixes (besides another similar set of B-suffixes) is combined with existential particles or the verb hwy 'be' to express predicative possession.

\footnotetext{
29 See Subsection 2.3.2.1. on the notion of case in the context of Neo-Aramaic.

30 See Subsection 2.3.1.2. on pragmatic functions.

$31 \quad$ See $\S 3.1 .2 .2 .$, §3.3.2.1., § 4.2.2.4., §4.3.2.1.

32 See $§ 2.2 \cdot 3 \cdot 2$.

33 Where prepositional pronouns and L-suffixes are conflated or where originally independent prepositional pronouns give rise to the innovation of new dependent person markers, this will be indicated and such person markers will be treated as another set of dependent person forms. See §3.1.2.2.

Gutman (2018) offers an overview of nominal annexation in NENA.
} 


\subsubsection{Adnominal Possession: ' $\mathrm{X}$ of $\mathrm{Y}$ '}

Nouns can be combined with other nouns in a possessor-possessee annexation construction, much like a genitive case in genitive relationships. In the default expression of nominal annexation the linker $d$ and its dialectical variants attaches either to the possessee, e.g. NENA (J. 'Amedia) šamm-ad babi 'the name of my father', or to the possessor, e.g. Țuroyo ú-əšmo $d$-ú-babayði 'the name of my father', where $u$ - is the definite article. The linker $d$ may also be augmented and degrammaticalize ${ }^{35}$ into the particle dod, e.g. xora dod babi 'a friend of my father'. Similarly, this linker may be inflected through the 'possessive'/pronominal suffixes, often with augmentation, to construct independent possessive pronouns, e.g. J. 'Amedia did-i 'mine', $d$-eni 'ours', Ṭuroyo did- $i$, did-an respectively. Such independent possessive pronouns can also feature in the annexation construction instead of or in combination with the dependent counterparts, e.g. J. 'Amedia lišana d-eni 'our language', xmar-ad did-i 'my donkey', bron-e did-e 'his own son' (Greenblatt 2011, 8o-81). Finally, truncated nominal forms can occur with elision of the final vowel, e.g. gora 'husband' $\rightarrow$ gor-'amti 'the husband of my aunt' (Greenblatt 2011, 71-75), reminiscent of the construct state (Gutman 2018).

\subsubsection{Predicative Possession: 'X has Y'}

Predicative possession is based on existential clauses introduced by the existential marker 'it- 'there is/are' and dialectal variants thereof. This particle is marked for negation by the negator $l a-$, e.g. $l a-y \underline{t} \sim l-i \underline{-}$ - 'there is/are not'/, and for past tense by -wa, e.g. 'it-wa 'there was/were'. Together with L-suffixes they express predicative possession akin to English have, e.g. Turoyo ono kat-li tre na ime 'I have two children'. (4) and (5) below show parts of the paradigms in Țuroyo and J. 'Amedia. As seen in example (4), the existential predicate may receive the TAM-marker $k$-, similarly to verbs. The verb hwy stands in a suppletive relation to these existential markers to express other TAM categories such as the future tense and subjunctive.

(4) Turoyo (SE Turkey, rural)

\begin{tabular}{|c|c|c|c|c|}
\hline & $\begin{array}{l}\text { PRESENT } \\
k i t(o)\end{array}$ & $\begin{array}{l}\text { PAST } \\
k \partial t-w a\end{array}$ & $\begin{array}{l}\text { NEGATIVE } \\
\text { layt }(o)\end{array}$ & SBJV \\
\hline ono & $k a t-l i$ & kát-way-li & lat-li & howe-li \\
\hline 3sg. hiye & kat-le & kát-way-le & lat-le & howe-le \\
\hline 3pl. hәппак & kat-te & kát-wa-lle & lat-te & howa-lle \\
\hline
\end{tabular}


(5) NENA (J. 'Amedia NW Iraq; Greenblatt 2011)

\begin{tabular}{|c|c|c|c|c|c|}
\hline & & $\begin{array}{l}\text { PRESENT } \\
\text { 'it } \underline{t}(\partial n)\end{array}$ & $\begin{array}{l}\text { PAST } \\
\text { 'วt-wa }\end{array}$ & $\begin{array}{l}\text { NEGATIVE } \\
\text { lit } \underline{(\partial n)}\end{array}$ & SBJV \\
\hline 1sg. & 'ana & 'at-li & 'át-wa-li & lat-li & hawe-li \\
\hline 3sg. & 'awa & 'at-le & ’át-wa-le & lat-le & hawe-le \\
\hline 3pl. & 'ani & 'วt-lu & 'át-wa-lu & lat-lu & hawe-lu \\
\hline
\end{tabular}

The L-suffixes are obligatory to cross-reference the possessor. Indeed, the coreferential nominal is never prepositional in NENA, but optionally in Turoyo. ${ }^{36}$ Compare for example ú-zlām-ano in (6a) with l-ú-malk-ano 'belonging to the king' in (6b) below:

(6) Țuroyo ('Iwardo, Ritter 1967-1971: 58/3, 57/12)
a. ú-zlàm-ano
kat-way-le
arbi kalote

the-man-DEM:MS EXST-PST-him forty daughter-in-law:PL

'This man had forty daughters-in-law.'

\section{b. ma kat-le l-ú-malk-ano \\ Q EXST-him to-the-king-DEM:MS \\ 'What does the king have?'}

Finally, dialects can have similar constructions combined with B-suffixes related to the preposition $b$ - 'in; at'. This can be used to express containment or having something inside, but are also equivalent to English can followed by the subjunctive, e.g.

$$
\begin{aligned}
& \text { c. ma ki-be } \quad \text { d-soyam- } \varnothing \\
& \text { what EXST-in.him sBJV-do } \text { IPFV }^{-3 M S} \\
& \text { 'What can he do?' (see Ritter 1967-1971:33-37). }
\end{aligned}
$$

\subsubsection{Nouns as Verbs and Verbs as Nouns: Non-verbal Clauses and Nominal Forms of the Verb}

As we turn to compound verbal constructions based on nominal forms of the verb such as the resultative participle (qțila) and the infinitive (qtala) or agent noun (qatola), we enter a space where the categorical distinction between (pro)nouns and verbs becomes 'fuzzy' in Neo-Aramaic.

36 See further Noorlander (2021) for a comparative study. 
The term 'copula', for instance, should not be mistaken for a copula verb 'be' in the strict sense such as found in Indo-European languages. In some dialects such as C. Artun (Hertevin, SE Turkey), it is still clearly more pronominal, while in other dialects such as Trans-Zab Jewish varieties it is more verbal (Khan 2012). The enclitic copula consists of pronominal elements and can denote syntactic roles like the E-suffixes and L-suffixes; for instance, in ditransitive constructions ${ }^{37}$ as well as verbal constructions with a nominal basis. This notwithstanding, such pronominal copulas do have verbal properties and sometimes even follow verb-like inflection, especially in the Trans-Zab Jewish varieties of NENA. They stand in a suppletive relation to the verb hwy 'be' in the expression of an indicative affirmative state of affairs in the present tense and have a negative and past counterpart, similarly to verbs. There generally is also a deictic or presentative counterpart alongside a special form of the copula used in relative clauses.

\subsubsection{Pronouns as Copulas}

Varieties of deictic elements and pronominal elements can be used to express the copula (cf. Diessel 1999) in NENA, Țuroyo and Mlaḥsó. Generally, the copula cliticizes to the predicate, i.e. attaches to it without modifying the stress, in the expression of the realis, non-negated present, unless it attaches to another constituent for pragmatic purposes. These unmarked dependent person markers closely correlate with independent pronouns, e.g. Turoyo hat áyko-hat 'Where are you-you?', ono hárke-no 'I-I am here'. Adjectives agree with their subject for number in predication and in the singular only also for gender.

It is common for NENA dialects to have a presentative or deictic set of copulas directing the attention to an observed state of affairs, i.e. more or less 'Look/I see here he is'. This deictic copula usually based on $h o(l)-, d u$ - or $k(a l)$ - as well as the negative copula with initial negator $l$-are independent and precede the verbal element, e.g. Țuroyo kali harke 'Look! I am here', latyo harke 'I am not here'. The past counterpart of the copula is expressed via an additional set usually containing -wa like verbal and predicative possessor constructions, e.g. Turoyo hárke-wayno 'I was here'. The form and usage of these copulas varies greatly across dialects (Khan 2012, 32). ${ }^{38}$ For example:

37 See Subsection 5.2.1.2. for examples in Țuroyo.

38 Examples of complete paradigms of the enclitic copula may be found in the overview at the end of this chapter and in $\S 3.1 .3 .3$. and $§$ 4.1.2.1. for respective dialect subgroups. 
(7) Țuroyo (rural, SE Turkey)

$\begin{array}{llllll} & \text { PRESENT } & \text { PAST } & \text { NEGATIVE } & \text { DEICTIC } & \text { RELATIVE } \\ \text { 1sg. } & -n o & \text {-wayno } & \text { latno } & \text { kalí } & \text { d-katno } \\ \text { 3sg. } & -y o & -w a & \text { latyo } & \text { kalé } & \text { d-katyo } \\ \text { 3pl. } & -n e & \text {-wayne } & \text { latne } & \text { kalón } & \text { d-katne }\end{array}$

(8) NENA (C. Marga, SE Turkey)

$\begin{array}{llllll} & \text { PRESENT } & \text { PAST } & \text { NEGATIVE } & \text { DEICTIC } & \text { RELATIVE } \\ \text { 1sg. } & \text {-wan } & \text {-wanwa } & \text { lun } & \text { wun } & \text { 'add-iwan } \\ \text { 3ms. } & \text {-ile } & \text {-wewa } & \text { lele } & \text { hole } & \text { 'add-ile } \\ \text { 3pl. } & \text {-ilay } & \text {-wiwa } & \text { lelay } & \text { holay } & \text { 'add-ilay }\end{array}$

The relationship between the copula and other resembling person markers is somewhat ambiguous. The third person markers that betray an /1/-segment in NENA are noteworthy, e.g. 3ms. -ile, and, for all practical purposes, are not considered another instance of L-suffixes. This does not mean that speakers always make a sharp distinction between copula forms like 'i-le and L-suffixes like -le, and a sharp distinction between the first/second person forms of the copula and the E-suffixes cannot always be maintained either (see § 3.4. and § 4.3.2.); the latter may even be identical in Țuroyo, e.g. 1sg. -no (copula) is identical to 1sg. - no (E-set).

The verb hwy 'be' is a suppletive pendant to these forms in other TAM contexts such as the subjunctive and future, e.g. Turoyo kt-owe-no harke ${ }^{~} \mathrm{I}_{\mathrm{M}}$ will be here'.

2.2.4.2 Nouns and Adjectives as (Compound) Verbs

The resultative participle is a verbal adjective inflected for number and only in the singular also for gender like other adjectives. The paradigm for stem I verbs is as follows:

(9) Resultative participle ${ }^{40}$

ms. qțil-a $(\sim q \partial t \underline{l}-a) \quad$ 'killed'

fs. $\quad$ qtal-ta $(\sim q t ̦ a l-t a)$

p.l qtil-e $(\sim q \partial t+l-e)$

39 hun $<$ *ho-wun.

40 The variant forms in parentheses are mainly found in Trans-Zab Jewish dialects, on which see Chapter 3 . 
The resultative participle can be combined with the copula to form an analytical perfect or resultative construction, as exemplified for C. Karamlesh (NW Iraq) below. Generally, the final vowels of the participle /a/ and /e/ and initial vowel of the copula /i/ undergo contraction to /e/, e.g. C. Karamlesh

$$
\begin{array}{ll}
\text { 3ms. } & \text { šqil-ele 'He has taken' }<\text { š́qila ile } \\
\text { šqil-ewa } & \text { 'He had taken' }<\text { šqila iwa }
\end{array}
$$

The perfect is used for transitive and intransitive verbs alike with the expression of grammatical agreement through the copula and participle: ${ }^{41}$

(10) C. Karamlesh (NW Iraq, Borghero 20o8, 80-81)

a. PRESENT AFFIRMATIVE INTRANSITIVE TRANSITIVE

3ms. zíl-ela 'He has gone' šqúl-ela 'He has taken'

3 fs. zált-ela 'She has gone' šqált-ela 'She has taken'

ipl. zíl-ewax 'We have gone' šqúl-ewax 'We have taken'

The resultative participle can also combine with the deictic copula, which always precedes it:

b.

DEICTIC

3ms. k-ilazila 'He has gone' k-ilašqila 'He has taken'

3fs. k-ilazalta 'She has gone' k-ila šqalta 'She has taken'

ipl. k-iwaxzile 'We have gone' k-iwax šqile 'We have taken'

For past tense reference, the past copula is used, for example:

$\begin{array}{lll}\text { c. } & \text { PAST } & \\ \text { 3ms. } & \text { šqúl-ewa } & \text { 'He had taken' } \\ \text { 3fs. } & \text { šqált-ewa } & \text { 'She had taken' } \\ \text { 1pl. } & \text { šqúl-ewaxwa } & \text { 'We had taken' }\end{array}$

The verb hwy 'be' complements the enclitic copula to form a perfect in various (dialect-dependent) moods and tenses such as the subjunctive or past irrealis. Apart from the perfect, an uninflectable agent noun or infinitive, generally together with the preposition $b$ - 'in (the process of)' e.g. bo-dmaxa 'in-sleeping', 
but also without, e.g. dmaxa 'taking', may be used to form a progressive, generally by a similar type of construction involving a copula.

C. Marga (SE Turkey)

$\begin{array}{llll} & \text { BASIC } & \text { DEICTIC } & \\ \text { PROGRESSIVE } & \text { dmáx-ele } & \text { hole dmaxa } & \text { 'He is sleeping' } \\ \text { PERFECT } & \text { dmíx-ele } & \text { hole dmixa } & \text { 'He has slept, is asleep' }\end{array}$

Not all dialects have fully grammaticalized such constructions, and the compound perfect and progressive are not necessarily both found in a given dialect, although they often do occur together (Khan 2007 d). In C. Karamlesh (Borghero 2008), for example, the compound progressive is marginal and the copula generally combines with the indicative qațal-, e.g.

$\begin{array}{llllll}\text { PROGRESSIVE } & k & -i l a & k- & s ̌ a q l-a & \text { 'She is taking' } \\ & \text { DEIX } & \text {-COP.3FS } & \text { IND } & \text { take } \text { PFv }^{-3 F S} & \\ \text { PERFECT } & k & -i l a & & s ̌ q a l-t a & \text { 'She has taken' } \\ & \text { DEIX } & \text {-COP.3FS } & & \text { taken-FS } & \end{array}$

Several dialects, especially in NW Iraq, employ a special preverbal TAM-marker $l \bar{a}$ alongside $n \bar{a}$, which is presumably a fossilized $3 \mathrm{fs}$. form of the copula $i l a$ ' $\mathrm{It}_{\mathrm{F}}$ is' (Khan 2007d), before qațal-and/or before qțil-, e.g. J. Dobe (NE Iraq Mutzafi 2004b, 26o)

$\begin{array}{llll}\text { PROGRESSIVE } & n \bar{a} & \text { palax }-\varnothing & \text { 'He is opening' } \\ \text { PERFECT } & n \bar{a} & \text { plax-le } & \text { 'He has opened' }\end{array}$

\subsubsection{Objects on 'Nouny' Verbs}

The marking of pronominal objects, if it occurs in the relevant dialect, is generally based on prepositions or on adnominal pronominal suffixes in the compound verbal forms expressing the perfect or progressive. ${ }^{42}$ The following major types of constructions are found among the NENA dialects: ${ }^{43}$

42 See Sections 3.4. and 3.5.3 on the alignment of arguments in these compound verbal constructions in Trans-Zab Jewish varieties, and Section 4.2. and 4.3.2. on their relationship to passive and transitive clauses in other NENA varieties.

43 Cf. Kapeliuk (2008). See Talay (2008, 318-323) for an overview of the Khabur valley dialects. These constructions have not undergone grammaticalization as such in Central Neo-Aramaic. 
a) an independent or dependent 'possessive' set;

b) an independent or dependent prepositional set.

Object indexes in the compound verbal forms based on qtala and qțila thus differ from those found with qațl- and qțil-, largely because of their ultimately nominal origin in the modern Aramaic system.

2.2.5.1 'Possessive' Person Markers

The originally nominal form of the verb takes object indexes from the otherwise adnominal set that denotes the possessor, cf. $b a b$-əh 'his father' with šqil-ặ 'taken him' below. The object is thus marked by the 'possessive' suffixes typical of nouns, for example:

(12) C. Baghdeda (Qaraqosh, NW Iraq; Khan 20o2a, 363)

a. k-ina šqil-a

DEIX-3PL taken-PL

'They have taken.' (lit. They are taken)

b. k-ina šqil-ah

DEIX-3PL taken-3MS

'They have taken him.' (lit. They are taken his)

The combination with full nominal objects in this construction type can also be based of adnominal possession. The object NP is marked by the genitive linker $-2 d$ typical of adnominal possessors in the annexation of noun phrases (Khan 2oo2a, $367-368)$ :

\section{c. k-ila xil-ad xabuša \\ DEIX-3MS eaten-LK apples}

'He has eaten apples.' (lit. He is eaten-of apples)

This also applies to pronominal objects in Jewish Zakho (Cohen 2012, 142-143). The latter are marked by means of the independent possessive pronouns based on did-, an augmented form of the linker -ad, to which 'possessive' suffixes are added, e.g.

(13) J. Zakho (NW Iraq; Cohen 2012, 142-143)

le-wan qțil-a dìd-a

NEG-COP.1Ms killed-Ms Poss-her

' $\mathrm{I}_{\mathrm{M}}$ have not killed her.' (lit. I am not killed hers) 
A copula may also be cliticized to this form depending on the dialect, e.g. C. Urmi (NW Iran; Khan 2016:387) šqálta-vat 'You ${ }_{\mathrm{FS}}$ have taken', šqált-u-vat 'You ${ }_{\mathrm{FS}}$ have taken him' (lit. $\mathrm{You}_{\mathrm{FS}}$ are taken his). The same holds for the compound progressive if it exists, but the original verbal noun generally does not inflect for agreement with its subject.

\subsubsection{Prepositional Pronominal Objects}

Prepositional person markers are based on the preposition ('al)l- in the majority of NENA dialects, but other prepositions such as ('ab) $b$ - also occur, especially in SE Turkey. The prepositional pronominal objects undergo increasingly deeper integration within the verbal form, e.g.

(14) C. Marga (SE Turkey)

ho-li grís -all-ux

DEIX-1SG pulled:MS -OBJ-2MS

'I have pulled you $_{\text {мs' }}$ ' (lit. Look-me pulled to-you)

(15) C. Țal (SE Turkey; Talay 2009, 312.106)

ho-lay qțil -abb-ay

DEIX-3PL killed:Ms -OBJ-3PL

'They killed them.' (lit. Look-them killed at-them)

The 'all-series or 'abb-series are regularly cliticized before the enclitic copula, e.g.

(16) C. Ashitha (SE Turkey; Borghero 2006, 195, 198)

qțil -all-ax -iwin

killed:MS -OBJ-2Fs -COP.1MS

'I have pulled you.' (lit. I am killed to-you)

(17) C. Tkhuma (Mazra, SE Turkey; Talay 20o8, 321)

grís -abb-e -le

pulled:Ms -овJ-3Ms -COP.3MS

'He has pulled him.' (lit. He is pulled at-him) 


\subsection{Defining and Identifying the Alignment of Who Did What to Whom}

Having concluded the description of the main inflectional morphology of NeoAramaic, this section proceeds to examine its clause structure in a typological perspective and introduces the theoretical preliminaries necessary for the more detailed dialectal studies in subsequent chapters.

Alignment, here, is considered first and foremost a property of constructions and not of a language as a whole (Comrie 1989, 114). ${ }^{44}$ Constructions are viewed as integrated wholes and independent units of grammatical meaning in the broadest and most common sense as form-meaning combinations at all possible levels of abstraction, ranging from word formation patterns to contextual pragmatic inferences of word order. ${ }^{45}$ In the application of the models of Comrie (1989) and Andrews (2007), the following five major distinctions will be made in clause structure. They will be explained in the following subsections.

(1) grammatical relations: subject, object;

(2) grammatical functions or syntactic roles: S, A, P, T, R, OBL;

(3) pragmatic functions: topic, comment, focus, others;

(4) semantic roles: agent, patient, theme, recipient, experiencer etc.;

(5) grammatical case morphology: nominative, accusative, dative, ergative, etc.;

(6) morphological properties (e.g. affixes) vs. syntactic behavioral properties (e.g. relativization);

(7) nominal marking (case, adpositions) vs. verbal person marking (agreement);

(8) independent vs. dependent person markers (pronouns).

The typological approach followed in this book allows for different alignment types to be manifested at the same time from different perspectives. Alignment may not necessarily show a single, uniform and rigid all-encompassing pattern. Rather it is specific to constructions in a particular language and can come across as chaotic, unstable and variable. Groupings or alignment patterns can be identified for different properties and from different perspectives, none of which is assumed to be a superficial manifestation of another deeper

44 Cf. Croft (2001, 168), Haig (2008).

45 See inter alia Goldberg (1995, 2001), Croft (2001), Booij (2010, 2013). 
type. Clause structure is thus not considered as an autonomous, complete and closed sentence-generating system, but a part of a larger total process of pairing form and meaning. Such an approach will inevitably lead to conclusions on Neo-Aramaic alignment different from other theoretical viewpoints (e.g. generative) found in the literature. This difference already begins with the definition of core grammatical functions (not be to confused with so-called thetaroles).

Andrews (2007) differentiates between grammatical functions and grammatical relations. Grammatical relations such as 'subject' and 'object' pertain to higher levels of abstraction and rule-based principles of grammar. The 'subject' is a structural, primitive ingredient that accumulates several primary semantic, pragmatic, morphological and syntactic behavioral properties. The grammatical functions such as S, A and P can be considered a 'subject', when the significant grammatical processes of sentence structure specifically apply to them. Such more abstract properties are commonly known as syntactic (or more specifically behavior-and-control) properties as opposed to their morphological building blocks (or more specifically coding properties).

In the examination of shared and unshared properties, grammatical functions can align or not align with each other. Typologists discern several distinct types of morphological alignment such as nominative-accusative and ergativeabsolutive, where shared coding properties align specific arguments with s. In syntactic alignment, the shared syntactic behavioral properties may also point to a particular grouping of $\mathrm{A}$ or $\mathrm{P}$ with $\mathrm{s}$.

\subsubsection{Arguments in the Clause and Their Core Functions}

As will be explained below, the core grammatical functions labelled s, A and $\mathrm{P} / \mathrm{O}$ as well as $\mathrm{T}$ and $\mathrm{R}$, are, respectively, reminiscent of (but not necessarily identical to) the notion '(S)ubject' (or '(O)bject') and the semantic roles '(A)gent', '(P)atient', '( $\mathrm{T})$ heme' and '(R)recipient'. These labels represent arguments of similar semantics and morphosyntax in the broad sense rather than the narrow sense. They are adapted to cover language-specific conventional marking of arguments beyond the primary clauses that instantiate them. The core functions A and $\mathrm{P}$ are defined by both their semantic and constructional prototypes, so that they, by definition, occur in a primary transitive construction (such as The cat killed the mouse). Thus, as will be explained, they are not to be conflated with the agent and patient of a passive voice construction.

As we will see, these grammatical functions, also known as syntactic roles, can also be assigned pragmatic functions such as topic and comment. Such discourse pragmatics deals with certain basic distinctions speakers make in 
the information flow and express what they consider more or less important to the conversation.

\subsubsection{Grammatical Functions: S, A, P, T and R}

Alignment typology presupposes a major classification of verbs in terms of basic combinability with slots to be filled by (pro)nominals, called arguments, representing the main participants entailed by the clause. Verbal constructions generally comprise up to three core arguments and are classified accordingly as intransitive, involving one argument, and transitive, involving two or more. The transitive is further divided into monotransitive and ditransitive constructions. Monotransitive verbs such as 'break' involve one argument, the object, in addition to the subject, typically the patient affected by an agent. Ditransitive verbs such as 'give' involve two additional arguments, one generally called 'recipient' representing the goal, receiver or addressee and the other generally called the 'theme' representing the gift.

Typologists generally presuppose a qualitative core of primary transitive verbs. Primary transitive verbs express physical causation such as 'break' and 'kill', i.e. those verbs where the agent acts in such a way that the patient is most obviously and definitively affected (Tsunoda 1985, 387). Following Comrie $(1978 ; 1984)$ and Andrews $(2007)$, alignment patterns will be described by means of the grammatical functions S, A and P (or O). ${ }^{46}$ (9) offers a simple definition in terms of semantic properties and primary syntactic functions following Comrie (1984).

(9) Definitions of s, A and P (following Comrie 1984)

$\mathrm{s}$ represents "the single argument of an intransitive predicate" (Comrie 1989,110 ), such as barti 'my daughter' in (11a) below, and this argument is therefore by definition its subject;

A stands for the agent, the actor (cf. Latin agens 'one who acts') in a primary transitive construction, such as the subject ú-gawrano 'this man' of the transitive verb 'kill' in (11b) below;

$\mathbf{P}$ is the label for the patient, the undergoing (cf. Latin patiens 'one who undergoes') or affected participant in a primary transitive construction, such as the object barti of 'kill' in (11b).

46 S, A and P are similar, but not necessarily equivalent to S, A and o in Dixon (1994) and Bickel (2011), see Haspelmath (2011a). Compare also X, Y and z in Lazard $(1994,1998)$ and A for actor and $\mathrm{U}$ for undergoer in Foley and Van Valin (1984). 
Subsequent, similar approaches also include accordingly $\mathrm{R}^{47}$ for the most recipient-like argument and $\mathrm{T}$ for the most theme-like argument in ditransitive constructions: ${ }^{48}$

\section{(10) Definitions of $\mathbf{T}$ and $\mathbf{R}$}

T stands for 'theme', the argument that is most like the entity that is transferred from one entity or location to another in a ditransitive construction, such as $u$-ktowo 'the book' in (11c) below;

R stands for 'recipient', the argument that is most like the receiver or ultimate goal of the transfer, such as l-barti ' to my daughter' in (11c) below.

(11) Țuroyo (SE Turkey)

[s] $\left[\begin{array}{ll}\mathrm{v} & -\mathrm{s}\end{array}\right]$

a. bart $-i \quad g$-mayt $-o$

(intransitive)

daughter:FS-my FUT-die ${ }_{\text {IPFV }}-3$ FS

SUBJECT

'My daughter will die.'

[A] $\quad[\mathrm{V} \quad-\mathrm{A}]$

b. ú-gawr-ano $\quad$ g-qoțal $\quad-\varnothing$

the-man-DEM:MSG FUT-kill ${ }_{\mathrm{IPFV}}-3 \mathrm{MS}$

AGENT

$[\mathrm{P}]$

bart-i

(monotransitive)

daughter:Fs-my

PATIENT

'This man will kill my daughter.'

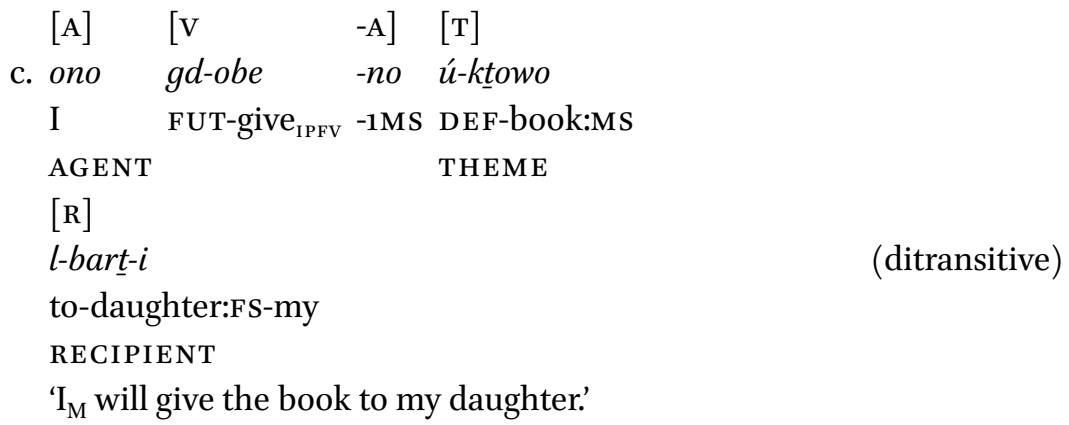

47 The R corresponds with $\mathrm{G}$ for 'goal' in other functionalist approaches like Croft (1990, 102). Sometimes $\mathrm{T}$ is used for 'target' instead, corresponding with the $\mathrm{R}$ here.

48 See Croft (1990, 2001), Siewierska (2003), Andrews (2007), Haspelmath (2005a). 
What is common to all Neo-Aramaic languages is the use of the E-series to encode both $\mathrm{S}$ and $\mathrm{A}$ and the L-series to encode $\mathrm{P}$ in alignment patterns completely based on qațal- in NENA or qoțal- in Țuroyo (e.g. ko-qŭțl-o-le 'She kills him'; see Section 2.1.).

Linguistically, it makes perfect sense to reduce the number of semantic roles to a few general grammatical functions, since languages tend to systematize the way they realize arguments (Andrews 2007). Strictly speaking, the A is defined according to what degree it is semantically like a typical agent and $\mathrm{P}$ to what extent it is semantically like a typical patient (or unlike a typical agent). Yet, somewhat confusingly, the terms ' $A$ ' and ' $P$ ' do not represent the merely semantic, participant roles of 'agent' and 'patient'. A and P stand for primary syntactic functions defined by both their semantic role and grammatical function. In other words, agents and patients are typically associated with, but not necessarily conditioned by, specific morphological and behavioral properties (Comrie $1989,111)$.

The core grammatical functions (s, A, P, T, R) are not presupposed to operate differently on a deep or surface level of the sentence in this approach. There are semantic prototypes associated with primary transitive actions that correlate with the conventionalized grammatical properties of such actions. ${ }^{49}$ Without A and $\mathrm{P}$, the construction is not considered transitive. This is not purely semantic. In Comrie's view, for instance, there are no deep or logical arguments A and P that surface or lexicalize differently in, for example, passivization. Even though both the agent and patient are expressed in a passive construction like The woman was hit by the man represented in (12b) below, the core argument the woman is in fact considered to be the s of an intransitive construction, while the man introduced using a by-phrase is understood to be oblique (Comrie 1989, 114). This means that A and P occur only in (12a), but not in (12b).

$[\mathrm{A}] \quad[\mathrm{v}] \quad[\mathrm{P}]$

(12) a. The man hit the woman.

(active)

AGENT TRANSITIVE PATIENT

[s] [V+PAss $] \quad[\mathrm{OBL}]$

b. The woman was hit (by the man). (passive)

PATIENT INTRANSITIVE AGENT

49 See Haspelmath (2011a) for a comparison of Comrie's approach with other approaches to alignment. 
The patient in the $P$ function of (12a) corresponds to the $s$ function of a passive voice construction, while the agent, if expressed, in the A function corresponds to the oblique, i.e. non-core, argument. The term oblique argument, abbreviated овц, will be used here in the same sense as Andrews (2007; cf. Keenan and Comrie 1977, 66) to refer to an argument specified by the verb, but expressed differently from the core grammatical functions S, A and P. This is different from adjuncts which are always considered oblique, but have a more adverbial function, such as on Monday in The woman was hit on Monday.

This might seem confusing to some readers at first glance, because, from a purely semantic role perspective, the woman would still be considered the patient and the oblique argument or prepositional phrase by the man expresses the agent. In this model of the functions of arguments, however, a passive construction like (12b) may offer insight into the treatment of $s$ in the language in question or into the semantic identity of agents and patients in a language, but it is not considered a primary example of how a language treats A and P.

Conversely, the so-called antipassive is an intransitive construction where the agent is expressed like $s$, the patient is omitted or possibly expressed as OBL, and the verb may have a special marker (Comrie 1978, 361-362, Cooreman 1994, 50). An illustrative example is given below from Dyirbal, an Australian language. Like the passive, its functions and restrictions differ from language to language, but as a construction it is largely uniform. Although semantically transitive, it is morphosyntactically intransitive and therefore lacks an A and P. The A of the transitive clause in the Dyirbal example is treated similarly to the $S$ of the verb in the antipassive construction in $(13 \mathrm{~b})$. The antipassive as such is the mirror image of the passive in making the patient rather than the agent as less salient, and the activity more central or identifiable (e.g. Cooreman 1994).

(13) Dyirbal (Australia, North Queensland; Comrie 1978, 358, 36o, 348, glossing slightly simplified, original source cited therein)
[P]
[A]
$[\mathrm{v}]$
a. Balam wudy $u$ baygulyaraygu dyayga-n $n^{y} u$
fruit-ABS man-ERG eat-TENSE
PATIENT AGENT TRANSITIVE
'The man eats fruit.'

(active)

$[\mathrm{s}] \quad([\mathrm{OBL}]) \quad[\mathrm{V}+\mathrm{ANTIP}]$

$\begin{array}{lll}\text { b. Bayiyara }(\text { bagum wudyu-gu) } & d^{y} \text { aygay-mari- } n^{y} u & \text { (antipassive) } \\ \text { man-ABS fruit-DAT } & \text { eat-REFL-TENSE } \\ \text { AGENT PATIENT } & \text { INTRANSITIVE }\end{array}$

'The man eats (fruit).' 
Thus both passive and antipassive are semantically transitive, but typically morphosyntactically intransitive. The passive decreases the valency and downplays the agent to the periphery as omissible (A vs. OBL), while the patient becomes the subject of an intransitive construction (P vs. S). This operation is also commonly known as a type of detransitivization, since the passive comprises an intransitive valence pattern. The reverse is known as transitivization, where the valence increases and the verbal construction becomes a transitive valence pattern.

Naturally, languages may categorize verbs and systematize semantic roles differently. S, A and P are grammatical functions meant to be heuristic tools to describe, compare and capture language- as well as construction-specific morphosyntactic groupings of arguments that are expressed in a more or less systematic fashion. The same coding strategies of primary transitives are conventionalized differently from language to language for verbs denoting mental causation such as 'frighten' and mental states such as 'see' and 'like' (Croft 1993). These may be treated like primary transitives, even though strictly speaking A and P semantically do not express an agent and patient, respectively.

Similarly, languages differ to what degree certain properties relevant to the agent's and patient's involvement in the event are also conventionalized in the grammatical structure. Some languages have specific constructions to express events where the agent acts unintentionally, for example, differently from those where the agents acts intentionally. ${ }^{50}$ Such unintentional interpretations, however, are generally contributed by the anticausative verb with an intransitive valence pattern typically denoting a spontaneous and, thus, uncontrolled event. ${ }^{51}$ Moreover, in many cases, the intentionality is not directly relevant to the clause structure of a language (Andrews 2007; Fauconnier 2012, 94-100), even in English, for example John broke his leg, where the intentionality is ambiguous. Similarly, partial or complete affectedness of the patient can be grammatically significant in languages favoring an intransitive construction for the less affected patient, ${ }^{52}$ but this is by no means a necessary requirement, cf. the transitive verb hit in English (Andrews 2007). As expected, we will also observe such phenomena in Neo-Aramaic languages, where not all verbs are compatible with the morphosyntax of primary transitive verbs.

Recently, Haude and Zúñiga (2016) argue that languages may have more than one basic transitive construction depending on discourse-pragmatic factors. Consequently, this makes it difficult to typify such alignment patterns.

$5^{\circ} \quad$ See DeLancey $(1984,1987)$, Croft (1991, 168), Kittilä (2005), Fauconnier (2011b, 2012).

$5^{1} \quad$ See Haspelmath (1993a), Kittilä (2005), Shibatani (2006), Fauconnier (2011b, 2012).

$5^{2}$ See Hopper and Thompson (1980), Tsunoda (1981, 1985), Dowty (1991), Testelec (1998). 
Neo-Aramaic languages, as we will see, also make use of several transitive constructions that could be characterized as basic depending on various factors and thereby challenge the more traditional monolithic view of alignment patterns. ${ }^{53}$

In the end, transitive clauses, by definition, include A and P. When these are lacking, the clause is considered intransitive, so that one of the arguments is considered s-like and/or something else, i.e. овL. Languages differ to what extent argument types are compatible with the syntactic functions $\mathrm{A}$ and $\mathrm{P}$.

\subsubsection{Pragmatic Functions: Topic and Focus}

Pragmatically speaking, a sentence contains a clausal topic referent, i.e. what is being talked about in the clause; the remaining elements are called the comment. On the level of discourse, the topic referent, once introduced, is familiar to the listener. When the discourse topic is the same across clauses, we speak in terms of topic continuity. In a sentence such as Mary is going to bed because she is tired, Mary is the topic and this is continued by she in the next clause, the referent being known/identifiable to the listener through the immediate context. Languages typically express the topic by means of anaphora (such as she) and sometimes by means of topicalization constructions, especially in the case of a switch of topic referent.

Focus, like topic, is another functional category in the information structure analysis of discourse. There are various types of focus, but, simply put, focus highlights some piece of information that somehow stands out because it is not presupposed, but asserted, while the remainder expresses what is presupposed to be familiar to the listener (Givón 1979, 1995; Lambrecht 1994). A focal argument typically expresses unexpected, new information, and may be contrasted with an alternative. A focal referent is most clearly represented by Mary in cleft constructions like It is Mary who stole my beer (and not John).

Pragmatic functions should not be conflated with grammatical functions. Generally speaking, Semitic languages can use independent pronouns to highlight a switch in topic reference or express a focal argument, i.e. narrow focus, and this typically concerns $\mathrm{S}$ and $\mathrm{A}$, but such independent pronouns can also mark other functions such as possessor in (14a) and (15a) or P in (14b) and (15b) for Țuroyo ${ }^{54}$ and NENA.

53 The concept of a primary construction appears to apply much less to constructions in which $\mathrm{T}$ and $\mathrm{R}$ occur. Languages may not have an obvious primary ditransitive construction at all (Malchukov et al. 2010b, 2).

54 See Waltisberg $\left(2016,95^{-97}\right)$ for a discussion of the syntax of independent pronouns in Țuroyo. 
(14) Țuroyo (SE Turkey)
a. ono әšm-i Xángir-yo
I name-my Xangir-COP:3MS
'As for me, my name is Xangir.' (Miden, Ritter 1967-1971, 73/56)
b. $g d-\breve{u} x l \quad-o \quad$-li óno-ste
FUT-kill ${ }_{\text {IPFV }}$-A:3FS -P:1SG I-ADD
'She will eat me too!' (Miden, ibid. 75/98)

(15) NENA (SE Turkey)
a. 'ana šomm-i 'ile Awiqam Šakro
I name-my cop:3Ms Awiqam Šakro

'As for me, my name is Awiqam Šakro.' (C. Shamsdin, Nochiya, SE Turkey; Talay 2009, 456.1)
b. 'ana qațl $\quad$-at $\quad-l i \quad w \quad$ 'aw qațl $\quad$-ət $\quad$-le I kill IPFV $_{\text {-A:2MS }}-\mathrm{P}: 1 \mathrm{SG}$ and he kill $_{\mathrm{IPFV}}$-A:2MS -P:3MS 'You can kill me and you can kill him.' (C. Tkhuma, SE Turkey; Talay 2009, 222.46)

Such personal pronouns are equivalent to zero-marked nouns in Neo-Aramaic as the unmarked citation form. They typically occupy clause-initial position and sometimes clause-final position, as shown in (14b), but are fully integrated as arguments in the clause as they focalize or topicalize the argument expressed through a dependent person marker. They can also occur between subject and predicate, e.g. Țuroyo əšm-i ono Yáhqqo-yo 'My name is Jakob' (Ritter 1967-1971, 116:37), or after the predicate, e.g. NENA lé-qațl-an-nux ana 'I $I_{\mathrm{M}}$ won't kill you' (C. Tal, SE Turkey; Talay 2009, 302.54).

The independent pronouns, therefore, are unmarked for a particular grammatical function, but typically express a pragmatic function (narrow focus). As illustrated in examples (14)-(15), there is a dependent person marker $(-i,-l i)$ that expresses the grammatical function of the independent equivalent.

Moreover, all arguments can undergo topicalization through fronting or left-dislocation, being only loosely integrated into the clause to introduce the clausal topic as a "forethought" (Givón 1976), indicated by two vertical strokes || in the example below. A verbal suffix on the verb refers back to it and resumes its syntactic role, such as the $\mathrm{P}$ in the following example: 
(16) Țuroyo (Miden, SE Turkey; Ritter 1967-1971, 75/323)

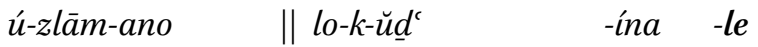

the-man-DEM:MS NEG-IND-know ${ }_{\text {IPFV }}$-A:IPL -P:3MS

'This man-, we do not know him.'

Thus, the unmarked citation form of full nominals and independent personal pronouns can be used to express all sorts of grammatical functions in NeoAramaic. Use of a zero-marked nominal or independent pronoun in a particular position in the sentence is motivated by the discourse and not by a grammatical function per se in Neo-Aramaic.

\subsubsection{Alignment: Morphological Properties}

The properties by which alignment patterns are identified are subdivided into morphological and syntactic (or coding and behavioral) properties in typological studies after Keenan (1976). The latter are syntactic constructions in a given language, which may be preferred or disfavored for particular functions, i.e. $\mathrm{S}$, $\mathrm{A}, \mathrm{P}$ etc., and are relevant to the determination of syntactic alignment types. We will review some of these syntactic behavioral properties in Subsection 2.3.3.

Only morphological alignment is pertinent to our discussion, since in many languages of the world syntactic properties group s and A accusatively. Still, some of these processes may be relevant to differentiate passive voice from ergative alignment.

The morphological properties generally involve a) and b) but also sometimes c) below:

a) nominal marking, i.e. case and/or adpositional morphology, 'flagging';

b) verbal person marking, i.e. agreement, 'indexing';

c) order of constituents, i.e. word order.

The morphological properties a) nominal case and/or adpositional marking and b) verbal person marking are the main morphosyntactic features examined in this monograph and will be further explained below. ${ }^{55}$ While case declensions and adpositional marking as well as verbal person marking are ultimately functionally equivalent as syntactic role signals and may even overlap (Siewierska and Bakker 2009; Kibrik 2012), they are distinct coding strategies. ${ }^{56}$ Indeed,

55 The terminology and accompanying ideas vary in the typological literature. Nichols (1986, 1992) distinguishes between head- and dependent-marking respectively, Andrews (2007) between NP-marking and cross-referencing, and more recent typological literature such as Malchukov et al. (2010a) between flagging and indexing.

$5^{6}$ Verbal person marking and prepositional marking, however, may sometimes be difficult to distinguish in Neo-Aramaic, cf. § 3.1.2.2. 
verbal person marking will be kept separate from case morphology. 'Case' is not treated here as an overarching abstract system of rules, so that cases and thematic roles are assigned by more deeply generalizable dependency relations between the verb and its complement in the generative sense. The latter leads to different analyses. Taking a generative approach, Doron and Khan (2010, 2012) and Barotto (2015), for example, use labels based on grammatical case such as ERG and ACC for what are called L-suffixes here and NOM and ABS for what corresponds to the E-suffixes in their analysis and glossing of person markers. ${ }^{57}$ This sometimes leads to confusing and cumbersome combinations of ERG-ACC and sometimes even ERG:NOM in the glossing of verbal forms.

Such case labels are not used for verbal person markers in this book, being reserved for nominal morphology. Case is treated as a morphological property of nouns distinct from verbal person marking. Hence, we do not speak of 'absolutive S-suffixes', 'accusative L-suffixes' etc., since this conflates verbal person marking as well as the syntactic role (s) with case morphology.

Word order will not be treated in full detail, as it is not always relevant in identifying an alignment type. Indeed, as will be explained in more detail in $\S$ 2.3.2.4, it would seem that word order potentially leads to ambiguity and, hence, will only be considered a morphological manifestation of alignment, when at least one of the argument's more or less fixed position relative to the verb is sufficiently distinctive as in, for example, a language like English.

In addition, while word order is generally subsumed under coding properties, it may also be considered a syntactic property instead (Haspelmath 2010). One may consider, for instance, the potential for word order shifts in interrogative, relative and/or passive clauses, processes subsumed under syntactic properties by typologists. Various other constituents in the sentence, e.g. interrogative pronouns, could affect argument placement in more complex constructions.

Moreover, word order is also clearly a discourse-sensitive property. It is relatively free and usually varies depending on the discourse properties of arguments irrespective of other coding properties in Neo-Aramaic (cf. Hoberman 1989, 100) like other languages with flexible word order (Givón 1995, 255-256). This notwithstanding, word order can be a contributing factor to argument discrimination in transitive constructions (see below).

All in all, the defining distinction of intransitive-transitive alignment patterns is the link between the single argument (s) of intransitive constructions and the two arguments (A, P) of primary transitive constructions through its

57 Similarly, Khan (2017) refers to 'ergative L-suffixes' and 'absolutive D-suffixes'. 
morphological and syntactic behavioral properties (Croft 2012, 259). In other words, what defines an alignment type is whether $\mathrm{S}$ is grouped with either $\mathrm{A}$ $(\mathrm{S}=\mathrm{A})$ or $\mathrm{P}(\mathrm{S}=\mathrm{P})$ in its coding (or behavior). The major types are:

a) $\quad(\mathrm{A}=\mathrm{S} \neq \mathrm{P})$ (nominative-)accusative: $\mathrm{A}$ is treated like $\mathrm{S}$;

b) $\quad(\mathrm{A} \neq \mathrm{S}=\mathrm{P})$ ergative(-absolutive) $::^{58} \mathrm{P}$ is treated like $\mathrm{S}$;

c) $\quad(\mathrm{A}=\mathrm{S}=\mathrm{P})$ neutral: all are treated alike.

Two other minor types can be distinguished, where $\mathrm{s}$ is grouped with neither $\mathrm{A}$ nor P:

d) $\quad(\mathrm{A} \neq \mathrm{S} \neq \mathrm{P})$ tripartite: all are treated differently;

e) $\quad(\mathrm{S} \neq \mathrm{A}=\mathrm{P})$ horizontal: $\mathrm{A}$ and $\mathrm{P}$ are treated alike.

The alignment patterns we review below can be and generally are represented by the following schemas given in Figure 1 on the next page. 59

The aforementioned differences among the various morphological and syntactic behavioral properties will be examined alongside these distinct alignment types. Alignment patterns need not at all be coherent in the sense that the same type is identified across all criteria. One alignment type can occur in morphology as opposed to syntactic behavior, or in nominal marking against verbal person marking; even verbal person marking can in itself diverge and show discrepancies depending on form and affix placement. Moreover, it is not uncommon that one particular alignment type only manifests in one particular grammatical domain. When the manifestation of one alignment pattern alongside another is conditioned by semantic and/or grammatical properties, we speak in terms of a split, such as the well-known cross-linguistic 'split-ergative' opposition between the accusative imperfective/present and the ergative perfective/past. This is of course the case in Neo-Aramaic, where alignment types that are consistently marked on the basis of qațl- always show accusative patterns, whereas only alignment types involving constructions at least partly based on qțil-, the historically resultative participle, ultimately yield non-accusative patterns.

Before we can address such splits, the alignment typology framework adopted here will be introduced, in which the morphosyntactic properties and manifestations of the constructions rather than the grammatical and/or semantic conditions per se are in focus. These conditions are discussed in the

$5^{8}$ It is common for nominative-accusative and ergative-absolutive alignment to be simply labelled according to the nominal marker of the isolated argument (accusative for the $\mathrm{P}$, ergative for the A).

59 See Comrie (1978, 332), Payne (1997, 140), Croft (2001, 138), Siewierska (2003), Velupillai (2012, 239). 


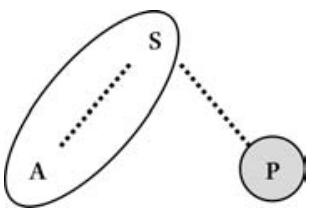

ACCUSATIVE

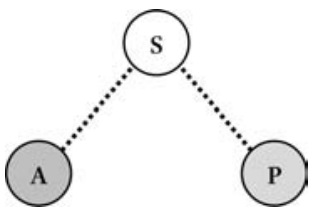

TRIPARTITE

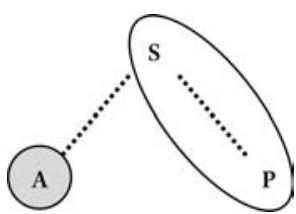

ERGATIVE

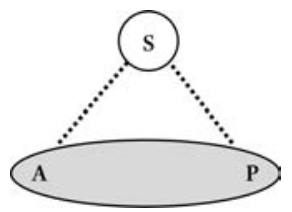

HORIZONTAL

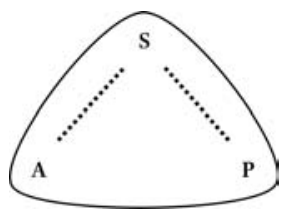

NEUTRAL

FIGURE 1 Monotransitive alignment schemas

subsequent chapters per dialect group: the Trans-Zab Jewish dialects of NENA in relation to the conditions of ergativity in Chapter 3 , other NENA dialects with respect to markedness, the distinction between passive and ergative and crosssystem harmony along splits in Chapter 4, and, finally, Ṭuroyo and Mlahsó in comparison to NENA, including ergative prepositional marking, in Chapter 5 .

2.3.2.1 Nominal Case and Adpositional Marking (Flagging)

Both nominal case inflection and adpositional marking indicate morphologically grammatical functions by manipulating or adding a morpheme to the nominal argument itself. The Semitic languages that exhibit case declension may serve as an example of how accusative alignment is typically manifested through case marking (see also Hasselbach 2013). Consider the example from Akkadian in (17) below. The nominative case (Akk. sg. -um, pl. $-\bar{u}$ ) groups s and $\mathrm{A}$, whereas the accusative case singles out $\mathrm{P}$ (Akk. -am).

(17) Akkadian (East Semitic, see Huehnergard 1997, 6-7, 19-18, 168-169, 98) $[\mathrm{s} \leftarrow \mathrm{NOM}]$

a. bitt-um i-mqut- $\varnothing$

(intransitive)

house-s:NOM:Ms s:3-fall ${ }_{\mathrm{PFV}}-\mathrm{S}: \mathrm{SG}$

'The house collapsed.'

$[\mathrm{A} \leftarrow \mathrm{NOM}] \quad[\mathrm{P} \leftarrow \mathrm{ACC}] \quad$ (transitive)

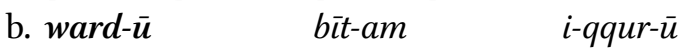

slave-A:NOM:MPL house-P:ACC:MS A:3-destroy ${ }_{\mathrm{PFV}}-\mathrm{A}: \mathrm{MPL}$

'The slaves destroyed the house.'

Whereas the accusative pattern groups $\mathrm{S}$ with $\mathrm{A}$, the ergative groups $\mathrm{S}$ with $\mathrm{P}$ $(\mathrm{A} \neq \mathrm{S}=\mathrm{P})$. In the following example from Standard Kurmanji (Northern Kurdish), 
the first case form $(e z, t u)$ marks both $\mathrm{s}$ and $\mathrm{P}$ and is generally referred to as the absolutive. The second case ( $\mathrm{min}, t e$ ) marks only A and is termed ergative.

(18) Kurmanji (Northern Kurdish, Turkey; Matras 1997, 617-618, glossing modified)

[S:ABS]

a. $e z$ $c ̧ \hat{u}-m$

(intransitive)

I:ABS went-s:1SG

'I went.'

b. $t u \quad c \hat{u}-y \hat{\imath}$

you:SG:ABS went-s:2SG

'You went.'
[A:ERG $]$ [P:ABS $]$
ez
saw-P:1SG
c. $t e$
dît-im
you:SG:ERG I:ABS saw-
'You saw me.' (lit. Your saw I)
d. $\min$
tu
$d \hat{\imath} t-\hat{\imath}$
I:ERG
you:SG:ABS saw-P:2SG
'I saw you.' (lit. Me saw you)

In typology, not only affixal case declensions, e.g. Akkadian NOM bitt-um, ACC bit-am etc., but also adpositional marking through, for instance pre- or postpositions or particles, e.g. Hebrew differential object marker 'et; Aramaic differential object marker $l-$, or a combination of the two are treated as one and the same type of coding property (cf. Comrie 2005, 398). Signaling or 'flagging' the NP in this general sense manifests itself in Neo-Aramaic by means of prepositions or particles.

Generally speaking, $\mathrm{s}$ and A are zero-marked, i.e. non-prepositional in NeoAramaic. The same holds for $P$ arguments, except when they are definite, compare (19a) and (19b) below. Overt prepositional marking of $P$, if it occurs in a Neo-Aramaic variety, is always conditional. When an NP ranks highly in discourse salience, it will tend to be marked by a preposition that is often the same as or historically related to the marker of recipients (see §4.4.2.). The Jewish Salmas differential object marker $a l$ - in (19b) below, for instance, signals the object of the following determined noun, aya lexma 'that bread'. As shown in (19b), prepositions, especially those marking full nominals, can be augmented with $-d$ - sometimes also its variant $-t$-, a linker that is often added before an immediately following vowel. 
(19) J. Salmas (NW Iran; Duval 1883, 120-121.19, 134.32, transcription modified)

[A]

a. ... aya brüna kudyöm
... DEM:SG boy:MS every.day
[P]

(Ø) lexma méndē- $\varnothing-v a$ bread:MS throw ${ }_{\text {IPFv }}-\mathrm{A}: 3 \mathrm{MS}$-PST '(Where) the boy would throw bread every day.'

$[\mathrm{A}]$

b. $y a$

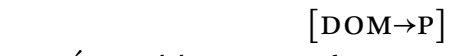

DEM:SG fish:FS eat ${ }_{\mathrm{PFV}}$-A:3FS DOM-LK DEM:SG bread:MS 'The fish ate the bread.'

Pronominal objects tend to be expressed independently by the same preposition (see $\S 3.1 .2)$ :

$$
\begin{aligned}
& \text { c. } k \text {-exl-ex al-ef } \\
& \text { IND-eat }_{\mathrm{IPFV}} \text {-A:1PL DOM-3MS } \\
& \text { 'We eat } \text { it }_{\mathrm{M}} \text { ' }
\end{aligned}
$$

Generally, when the marking of arguments is conditional as in differential object marking, the pattern with overt marking is taken to represent the more basic alignment type.$^{60}$ In this case, only P is marked in such a way, so that the nominal marking above can be characterized as accusative $(\mathrm{A}=\mathrm{S} \neq \mathrm{P})$.

While definite Ps can be flagged, $\mathrm{s}$ and A are typically zero-marked in NeoAramaic. There is no overt nominal marking that indicates their role. What indexes their respective role, is the verb itself.

\subsubsection{Verbal Person Marking from Different Perspectives (Indexing)}

Person markers, also known as anaphoric pronouns, may be dependent (or bound, i.e. affixal or clitic) or independent (i.e. free). Independent person markers are generally included in the nominal system and are required when dependent equivalents are not available. ${ }^{61}$ Only dependent person markers qualify as indexes of a coreferential nominal. ${ }^{62}$

In alignment typology, agreement involves co-referencing the person, number and/or gender features of an argument in the clause. Agreement is neither necessarily confined to core grammatical functions nor confined to verbs. ${ }^{63}$

6o See Comrie (2005), Siewierska (2005), Malchukov et al. (2010).

61 Unversal G. in Haspelmath $(2013,222)$.

62 Universals A. and B. in ibid.

63 See Corbett $(2003,2006)$, although there is no universally accepted definition of agree- 
The controller of agreement is the co-nominal referent, i.e. a full nominal or independent pronoun, which determines the agreement. The target it controls can be another constituent, which for our purposes is always a verbal form taking a person marker or index: thus we are dealing with verbal person marking.

Verbal person marking is not restricted to $\mathrm{S}$ and $\mathrm{A}$ in Aramaic. Hence, as shown in the Christian dialect from Aradhin (20) below, when we consider the P laxma 'bread', the co-nominal referent is marked by the verb ypy 'bake' through the person index -le agreeing with it. Such person indexes are traditionally known as pronominal suffixes, i.e. pronominal copies, in Semitics and typically occur when P, i.e. object argument, is definite (see Khan 1988).

(20) C. Aradhin (NW Iraq; Krotkoff 1982, 94.82)

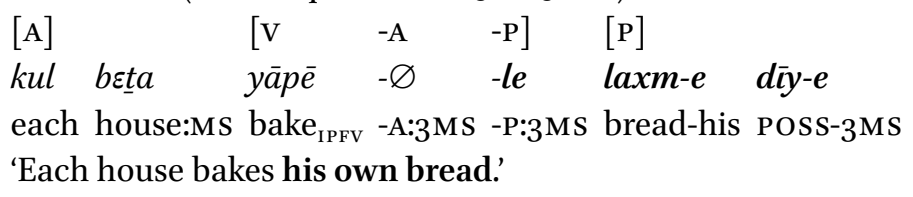

Some linguists make a sharp distinction between affix and clitic as subtypes of bound morphology. The distinction is, however, taken here to be fuzzy and not clear-cut (see Haspelmath 2011b), although, naturally, not all bound morphology will show the same usage patterns or the same effect on stress. It is rather a matter of a continuum, so that no strict categorical demarcation is implied here. The L-suffixes, for instance, do have certain clitic-like properties (see § 2.3.3.3.) that set them apart from the E-suffixes and 'possessive' suffixes and make them more like enclitic elements in Neo-Aramaic.

Person indexing through dependent person markers should not be mistaken for pronouns in the strict sense, as they are not necessarily anaphoric or cataphoric noun substitutes. ${ }^{64}$ Importantly, the nominal coreferent is always the same constituent in the clause for person indexes, while this is not required for anaphoric pronouns. The full co-nominal laxma in (20) can, for instance, be absent, so that the L-suffix on the verb expresses an anaphoric pronoun:

ment (Siewierska 2004, 120). See also Haspelmath (2013), following Lazard (1998) and drawing on Siewierska (2004), on defining person indexing.

64 See Siewierska (2004, 121-127) for a discussion of the differences between pronouns and agreement markers. See Haspelmath (2013) on the distinction between pronouns as noun substitutes proper (English he) and argument indexes. 
(21) C. Aradhin (NW Iraq; Krotkoff 1982, 94.82)

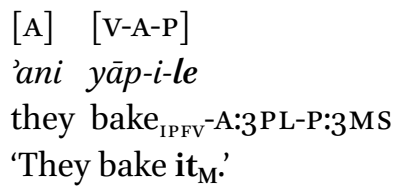

In this analysis, therefore, expressing the pronominal object through the Lset of dependent person markers is a strategy morphologically distinct from expressing the pronominal object through an independent prepositional pronoun, such as al-ef in J. Salmas above in (19c).

This verbal indexing in (19) and (20) is different from languages where the co-nominal is always lacking and an object index is always pronominal. An object index like - $h u$ in Classical Arabic, for instance, typically lacks a conominal, so that clauses like

$$
\begin{array}{cccc}
\text { *** rajay } & -t u & -h u & \text { l-kalba } \\
\text { saw } & -\mathrm{A}: 1 \mathrm{SG} & -\mathrm{P}: 3 \mathrm{MS} & \mathrm{ART}-\mathrm{dog}: \mathrm{MS}
\end{array}
$$

are not grammaticalized as such for 'I saw the dog' but rather convey 'I saw him, - the dog. The shift from such a pronominal index or pro-index to a cross-index is a well-known diachronic development found in Semitic languages that lost case declensions. Originally stressed independent pronouns become unstressed and increasingly dependent on the host, e.g. the verb, to end up as verbal person markers via topicalization constructions (cf. Givón 1976; Lehmann 1988). The person marker becomes increasingly obligatory in more routine-driven grammatical functions as fully integrated person indexes (see further below).

When the coreferential nominal is optional, as illustrated for both A and P in (19a), this is generally known as pro-drop. This is referred to here as crossindexing, following Haspelmath (2013). Thus, a verbal predicate like yāp-i may occur with a subject $\mathrm{NP}$, an independent pronoun often with pragmatic force (see $§$ 2.3.1.2.), or without a co-referent, e.g. C. Aradhin

$$
\begin{array}{lll}
\text { baxtāta } & y \bar{a} p-i & \text { 'Women are baking.' } \\
\text { 'ani } & y \bar{a} p-i & \text { 'THEY are baking.' } \\
& y \bar{a} p-i & \text { 'They are baking.' }
\end{array}
$$

The E-suffix functions as a cross-index of A, the co-nominal not being obligatory.

At the same time, there is a difference between the absence and presence of cross-indexing for a particular grammatical function in itself. The indexing of $\mathrm{P}$, 
for instance, is always conditional in Aramaic and depends mainly on definiteness. When a nominal $\mathrm{P}$ argument is indefinite, it will not be cross-indexed. Compare (22a) below with (22b):

(22) C. Aradhin (NW Iraq; Krotkoff 1982, 94.82)<smiles>[AlH2]</smiles>

a. $y \bar{a} p-i \quad$ laxma

bake $_{\mathrm{IPFV}} \mathrm{A} \mathrm{A} 3 \mathrm{3PL}$ bread:MS

(indefinite object)

'They bake bread.'
$[\mathrm{A}] \quad\left[\begin{array}{lll}\mathrm{V} & -\mathrm{A} & -\mathrm{P}\end{array}\right]$
b. kul beța yāpē $-\varnothing \quad$-le
each house:Ms bake ${ }_{\text {IPF }}$-A:3MS -P:3MS
(definite object)
[P]

\section{laxm-e dìy-e \\ bread-his LK-3MS \\ 'Each house bakes his own bread.'}

By contrast, such indexing of $s$ and $A$ is generally not optional or conditional in Aramaic. While forms like yāp- ' 'They bake' can easily occur in transitive constructions without an object L-suffix such as (22a) above, it is not possible to omit the E-suffix when a co-nominal is present, e.g.

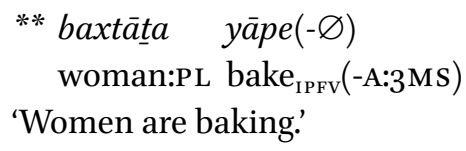

The potential for overt indexing in general is thus greater for $\mathrm{s}$ and $\mathrm{A}$.

We could therefore characterize this verbal person marking as basically accusative for multiple reasons. Indeed, verbal person marking can be viewed from different perspectives: Siewierska (2003) and Bickel et al. (2013) assume the following perspectives. The first question is whether indexing is possible at all. If so, then in what form and to what extent? The markers are compared not only in terms of morphological marking, i.e. what particular set of person markers, but also in terms of the relative position or left-to-right order of affixes, ${ }^{65}$ e.g. the markers are prefixal for $\mathrm{S}$ and $\mathrm{A}$, but suffixal for $\mathrm{P}$. It may also be rele-

65 Cf. Kibrik (2012). However, affix position is confined to clear distinctions between prefixal and suffixal forms in this monograph, since the relative position of dependent person forms that are all prefixal or all suffixal is not clearly significant for alignment, see $§$ 2.3.2.3. 
vant how the arguments align in triggering a verbal person marker in general, e.g. only $\mathrm{S}$ and A trigger agreement but never $\mathrm{P}$, or under specific conditions, e.g. agreement with $\mathrm{S}$ and $\mathrm{A}$ is conditioned by word order or cross-indexing of the $P$ is conditioned by definiteness.

These criteria can be illustrated by examining example (17) again from Akkadian, but now from the perspective of verbal person marking. The alignment of verbal person marking can be viewed from the perspective of:

a) morphological marking;

b) affix order;

c) trigger potential;

d) conditionality.

(23) Akkadian (East Semitic; Huehnergard 1997)

[s] [s-v-s]

a. bit-um i-mqut- $\varnothing$

(intransitive)

house-S:NOM:MS s:3-fall ${ }_{\mathrm{PFv}}-\mathrm{S}: \mathrm{SG}$

'The house collapsed.'

$[\mathrm{A}] \quad[\mathrm{P}] \quad[\mathrm{A}-\mathrm{V}-\mathrm{A}]$

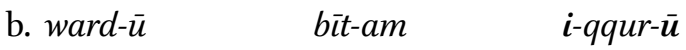

(transitive)

slave-A:NOM:MPL house-P:ACC:MS A:3-destroy ${ }_{\mathrm{PFV}}$-A:MPL

'The slaves destroyed the house.'

[A-V-A-P]

c. $\bar{\imath}-q q u r-\bar{u}-\check{s} u$

$\mathrm{A}: 3-$ destroy $_{\mathrm{PFV}}-\mathrm{A}: \mathrm{MPL}-\mathrm{P}: 3 \mathrm{MS}$

'They destroyed it $_{\mathrm{M}}$ '.

First, $\mathrm{s}$ and $\mathrm{A}$ align accusatively at least in terms of morphological marking $(i-$ $\mathrm{V}-\varnothing, i-\mathrm{V}-\bar{u})$, i.e. the same set of person markers is used to express both. When $\mathrm{P}$ is expressed by a pronominal object suffix, as shown in (23c), a different set is used (e.g. -šu).

Secondly, the affix order allows for some gender and number indexing of $s$ and A to follow the verbal stem $(-\varnothing,-\bar{u})$, but the verbal person marking is otherwise prefixal for $\mathrm{S}$ and $\mathrm{A}$, but suffixal for P. Again, the alignment is accusative in terms of affix order.

Finally, $\mathrm{s}$ and A are also grouped in terms of trigger potential and conditionality, since nominal P arguments do not trigger indexing at all, as shown in (23b). The alignment of the verbal person marking in Akkadian as such is accusative throughout. 
The accusative type can be contrasted with the ergative example from Standard Kurmanji in (18) above. Only s and P are indexed by the same set immediately following the verbal stem (e.g. -im, $-y \hat{\imath})$. Agreement, therefore, is ergative throughout in morphological marking, affix order, trigger potential and conditionality. Pronouns are expressed independently in Kurmanji. Naturally, dependent person markers alone can also be manifested ergatively, as illustrated by the following example from a Gorani dialect, another Northwest Iranian language. $S$ and $P$ are marked through the same set of affixes $(-\varnothing)$ immediately following the verbal stem, while A is expressed through a different set of clitics $(-\check{s})$, which, as indicated in (24c), can move to a preverbal host if present.

(24) Gorani Hawramani Luhon (NE Iraq, W Iran; Mackenzie 1966)

[v-s]

a. $w i t-\varnothing$

(intransitive, no clitic)

sleep $_{\mathrm{PST}} \mathrm{S}: 3 \mathrm{MS}$

'He slept.'

[V-P-A]

b. $d i-\varnothing-\check{s}$

(transitive, A attached to verbal form)

see ${ }_{\mathrm{PFV}}-\mathrm{P}: 3 \mathrm{MS}-\mathrm{A}: 3 \mathrm{MS}$

'He saw him.' (lit. Him saw he)

$[\mathrm{P} \quad \mathrm{-A}] \quad[\mathrm{V}-\mathrm{P}]$

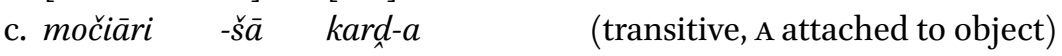

instruction -A:3PL $\mathrm{do}_{\mathrm{PFV}}-\mathrm{P}: 3 \mathrm{FS}$

'They instructed her'. (lit. Them instructed she)

The trigger potential of verbal person marking may also be graded in terms of obligatoriness, i.e. if agreement is possible, it may be optional or obligatory:

impossible $>$ optional $>$ obligatory

Recently, Haig (2018) has shown that there is a notable cross-linguistic tendency for object indexes to remain conditioned, once they have grammaticalized. This also holds for Aramaic throughout its long history. Despite the variation we find in terms of morphological marking in the verb and despite the alignment splits we encounter, object indexing is always conditioned in Neo-Aramaic, just as it has been in pre-modern Aramaic varieties. What sets one dialect (bundle) apart from the other is first and foremost the morpholog- 
ical marking. In other words, the trigger potential has essentially never really changed, but the morphological marking did.

In the approach taken here, the aforementioned criteria represent different perspectives in which verbal person marking can express an alignment pattern and they do not necessarily mean that one is only a surface phenomenon of the other. This inevitably leads to a different analysis if this distinction is overlooked.

Hemmauer and Waltisberg (2006), for instance, argue that the perfective past in Țuroyo is only superficially ergative, since certain properties point to an underlying accusative pattern, and, hence, verbal person marking is essentially accusative. This is where an important difference between our approach and theirs comes into play. First, a distinction between deep and superficial alignment does not exist here. The verbal person marking itself can simply be viewed from different perspectives (see above).

To illustrate, ergative verbal person marking is found in Țuroyo, as given in $(25){ }^{66}$ The E-set (-o marks S and P, but the L-set marks A (-le).

(25) Turoyo (SE Turkey)
a. ftih
(intransitive)
open $_{\mathrm{PFV}}-\mathrm{s}: 3 \mathrm{Fs}$
'It ${ }_{\mathrm{F}}$ opened (by itself).'
b. ftih $\quad-o \quad-l e$
open $_{\mathrm{PFV}}-\mathrm{P}: 3 \mathrm{FS} \quad$-A:3MS
(transitive)
'He opened $\mathrm{it}_{\mathrm{F}}$ ' (lit. Him opened $\mathrm{it}_{\mathrm{F}}$ )

When full NPs are present, the cross-indexing is not obligatory and may be even lacking altogether even when the object is definite. This, by contrast, does not apply to the indexing of $\mathrm{s}$ and $\mathrm{A}$. Compare 'ayne in (26a) and (26b) below. This, however, only shows that the trigger potential is accusative, as P does not trigger agreement to the same degree as $\mathrm{S}$ and $\mathrm{A}$. This relevant observation does not alter the facts about the morphological marking.

66 This will be discussed in greater detail in Chapter 5 . Recently, Waltisberg (2016, 20, 176) even denied any manifestation of ergativity whatsoever in Turoyo. This is not the conclusion I have reached in my own research. 
(26) Țuroyo (Miden, SE Turkey)

$\left[\begin{array}{lll}\mathrm{V} & -\mathrm{A}\end{array}\right] \quad[\mathrm{P}]$

a. ftah -le 'ayn-e

open $_{\mathrm{PFV}}$-A:3MS eye-his

'He opened his eyes.' (Ritter 1967-1971, 81/18)

$[\mathrm{s}] \quad[\mathrm{v} \quad-\mathrm{s}]$

b. 'ayne $d$-ú-babo ftị $-i$

eyes of-the-father open ${ }_{\mathrm{PFv}}-\mathrm{S}: 3 \mathrm{PL}$

'Father's eyes opened.' (ibid., 57/237)

Furthermore, Waltisberg $(2016,20,176)$ points out that the inflectional base of certain intransitive verbs, i.e. $\mathrm{CaCiC}$ - as in damix-o 'She fell asleep', differs from that of transitive verbs, i.e. CCiC- as in ftih-o-la 'She opened it $_{\mathrm{F}}$.' There is a major subclass of verbs belonging to stem I that takes an alternative 'perfective' base qațil-against qțil-, e.g. damix-o 'She fell asleep' instead of ** dmix-o like ftih-o 'It opened'. NENA does not have a stem corresponding to Turoyo damix- derived from ${ }^{*} \mathrm{C} a \mathrm{CC} \bar{\imath} \mathrm{C}$, i.e. *dammīk-. The different inflectional base for certain intransitive verbs in Țuroyo, however, is an integral part of the same system as qțiland does not alter the facts about the sets of person markers responsible for expressing the syntactic roles, which evidently align ergatively in morphological marking.

Hence, as we will see, the morphological marking makes one dialect different from the other as well as from the rest of Semitic. The morphology is therefore more significant for alignment from a comparative perspective.

\subsubsection{Order of Independent and Dependent Argument Coding}

Malchukov et al. (2010b) discuss how word order leads to ambiguity for alignment typology. This also holds for the relative order of dependent person markers. ${ }^{67}$ Word order and the order of person affixes or clitics are obviously not completely parallel. It is, for instance, more likely that independent (pro)nominal arguments would vary in position relative to the verb than dependent person markers relative to the verbal base. This notwithstanding, they both lead to ambiguous conclusions for argument grouping, i.e. $\mathrm{S}=\mathrm{A} \neq \mathrm{P}$. Word order and affix order are not helpful as alignment determinants, if all the arguments are expressed on the same side of the verb(al stem).

Consider the Arabic example of accusative alignment given below.

67 Cf. Siewierska (2003). 
(27) Modern Standard Arabic (Central Semitic, Kász 2015, 336)

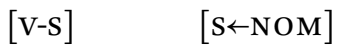

a. saqat-a l-walad-u

(intransitive)

fall $_{\mathrm{PFV}}-\mathrm{S}: 3 \mathrm{MS}$ ART-boy:MS-S:NOM

'The boy fell.'

$[\mathrm{V}-\mathrm{A}] \quad[\mathrm{A} \leftarrow \mathrm{NOM}] \quad[\mathrm{P} \leftarrow \mathrm{ACC}]$

b. darab-a l-walad-u l-kalb-a

(transitive)

beat $_{\mathrm{PFV}}-\mathrm{A}: 3 \mathrm{MS}$ ART-boy:MS-A:NOM ART-dog:MS-P:ACC

'The boy beat the dog.'

$\left[\begin{array}{ll}\mathrm{V} & -\mathrm{s}\end{array}\right]$

c. saqat $-a$

(intransitive)

fall $_{\mathrm{PFV}}-\mathrm{S}: 3 \mathrm{MS}$

'He fell.'

$\left[\begin{array}{lll}\mathrm{V} & -\mathrm{A} & -\mathrm{P}\end{array}\right]$

d.

(transitive)

beat $_{\mathrm{PFV}}-\mathrm{A}: 3 \mathrm{MS}-\mathrm{P}: 3 \mathrm{MS}$

'He beat him.'

A and P obviously do not occupy the same slots in the clause or in the chain of verbal affixes. Nevertheless, it is unclear to what argument $s$ would be said to align. $s$ and A arguably align with each other by being immediately adjacent to the verb. At the same time, however, $\mathrm{s}$ and $\mathrm{P}$ could be said to align, since both arguments occupy the final position of the construction. By the same token, the order of suffixal verbal indexes is also ambiguous. $\mathrm{s}(-a)$ and $\mathrm{A}(-a)$ are both closer to the verbal stem than $\mathrm{P}(-h u)$ in $(27 \mathrm{~d})$. The $\mathrm{P}$ index, however, arguably also aligns with $\mathrm{s}$, as both constitute the final suffix of the verbal form. Nevertheless, the morphological marking itself is transparent and clearly accusative.

By contrast, affixal position for the alignment of indexes is clearly relevant in the following intransitive and transitive constructions from Chorti, a Mayan language (Guatamala), taken from Siewierska $(2003,343)$. The coding of $\mathrm{s}$ matches that of $\mathrm{P}$ both in form (-et) and position (suffixal). The person markihng of $\mathrm{A}$ is distinct in form ( $a$ - vs. $-e t$, in- vs. -en) as well as position (prefixal vs. suffixal). The indexing thus patterns ergatively on all accounts. 
(28) Chorti (Mayan, Guatamala; Siewierska 2003, 343, original source cited therein, glossing adapted)

This does not rule out, of course, that word order and affix/clitic order are possibly significant contributors to argument discrimination in transitive constructions (i.e. A before/after P). Word order is arguably considered relevant in languages like English, for example. Morphologically, S, A and P are all treated in the same way in English, apart from most of the pronouns and the third person $-s$ in the present simple. Distinct morphological marking of the arguments is otherwise absent, so that the alignment is neutral in terms of both nominal marking and verbal person marking $(\mathrm{A}=\mathrm{S}=\mathrm{P})$. Word order, however, clearly contributes to role discrimination. P typically follows the verb, but S and A occupy pre-verbal position, as observed in the translation of the examples above. Thus English alignment could be characterized as accusative in terms of word order: pre-verbal s and A vs. post-verbal P.

In fact, word order in general is more geared toward information processing in discourse. For instance, arguments placed consistently before the verb (e.g. A-P-V) are cross-linguistically more likely to be distinguished through case or adpositional marking than those consistently placed at either side of the verb (e.g. A-V-P, P-V-A). The obvious reason that Siewierska and Bakker (2009) give for this observation is that the linearization of arguments in verb-final constructions contributes much less to role discrimination than distinct nominal morphology (cf. de Hoop and Lamers 20o6).

Neutral alignment can also manifest itself through non-distinct morphological marking instead of its absence. The neutral type, on the other hand, is sometimes understood solely as the absence of dependent person markers (e.g. Siewierska 2004, 52), since the phonologically non-distinct person indexes gen- 
erally do display a distinct affix position, as exemplified below in the Papuan language Reefs. Here, $\mathrm{s}$ is prefixal, while A is suffixal, even though they are phonologically non-distinct, i.e. dyi-V vs. V-dyi. ${ }^{68}$

(29) Reefs (Papuan, Eastern Outer Islands; Siewierska 2003, 343-344, original source cited therein, glossing slightly adapted)
$\left[\begin{array}{ll}\mathrm{s}- & \mathrm{v}\end{array}\right]$
a. $d y i^{-} \quad k i$-egi
S:IDU:INC ASP-cry
'We cry.'
$[\mathrm{P}] \quad[\mathrm{V} \quad-\mathrm{A}]$
b. nyenaa ki-bwaki - dyi
stick ASP-break -A:1DU:INC
(intransitive)
'We broke the stick.'

Non-distinct phonological verbal person marking is also found in Neo-Aramaic. The Jewish dialects of Iranian Azerbaijan on the eastern periphery such as Urmi and Salmas and Turkish Christian dialects on the western periphery such as Borb-Ruma (Bohtan; Fox 2009), Artun (Hertevin, Jastrow 1988), Hașanan (Hassane, Jastrow 1997; Damsma forthcoming), Umṛa and Jinnet (Noorlander field notes) use the L-suffixes for all grammatical functions in the preterit constructions based on qtil-. For example:

(30) C. Borb-Ruma (Bohtan, SE Turkey; Fox 2009)
$\left[\begin{array}{ll}\mathrm{v} & -\mathrm{s}\end{array}\right]$
a. qam -li
rise $_{\mathrm{PFV}}-\mathrm{S}: 1 \mathrm{SG}$
'I rose.' (lit. Me rose)
(intransitive)
$\left[\begin{array}{lll}\mathrm{V} & -\mathrm{A} & -\mathrm{P}\end{array}\right]$
b. $p$ táx $\quad-l i \quad-l e$
open $_{\mathrm{PFV}}-\mathrm{A}: 1 \mathrm{SG}-\mathrm{P}: 3 \mathrm{MS}$
'I opened $\mathrm{it}_{\mathrm{M}}$ '. (lit. Me opened him)
(transitive)

68 The relative order of arguments can also be free in e.g. Bantu languages (Siewierska 2003, 264). 
The transitive construction takes two L-suffixes. The L-suffixes are used in a strict order: L-suffixes that mark the patient always follow the L-suffixes that mark the agent, so that V-P-A affix arrangements like

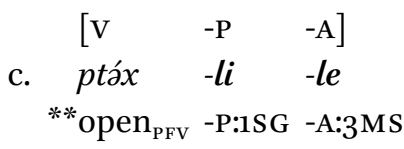

$$
\begin{aligned}
& \text { ***He opened me.' }
\end{aligned}
$$

do not occur, but only V-A-P.

The extent to which one includes the order of affixes can affect the way one identifies alignment patterns and lead to ultimately different analyses. Coghill $(2016,64,90)$, for instance, subsumes this type under accusative alignment, presumably because of the relative position of the set of suffixes that she considers a determinant for alignment. Neutral alignment is sometimes confined to the absence of overt verbal person marking (e.g. Siewierska 2004, 52). Still, this completely ignores the fact that they are treated alike in terms of morphological marking. The same set is used for all grammatical functions, an important difference with, for example, the accusative pattern found in qațl-based constructions. The position of affixes seems to me only significant if the position relative to the verb is distinct for both $\mathrm{A}$ and $\mathrm{P}$ (i.e. prefixal vs. suffixal). S, A and $P$ are all suffixal in the case of $(26 \mathrm{c})$ and (29). Thus, although the relative linear position evidently supports role discrimination, it cannot be unambiguously applied as a criterion to determine which suffix is grouped with s: it could arguably be either. Phonologically non-distinct person markers, therefore, are in principle also treated under neutral alignment here. ${ }^{69}$

\subsubsection{Other Morphological Alignment Types}

Cross-linguistic studies ${ }^{70}$ show that neutral and accusative alignment turn out to be the most common, followed by the ergative type. ${ }^{71}$ The other two minor alignment types are tripartite and horizontal alignment. A major difference between the latter two and accusative, ergative as well as neutral alignment is that $\mathrm{s}$ does not group with any other argument and is isolated.

Tripartite alignment is the mirror image of the neutral pattern. s, A and $\mathrm{P}$ are all treated differently $(\mathrm{A} \neq \mathrm{S} \neq \mathrm{P})$, as illustrated in the following example from Yazgulyami, a Pamir language (East Iranian). The independent pronouns

69 Cf. Siewierska (2003).

70 See Siewierska (2004, 2005), Comrie (2005), Croft (2012, 259), Velupillai (2012, 243).

71 See Section 3.2. on ergativity and alignment splits. 
exhibit distinct nominal marking. The first person singular would be $\check{z}$-mon in the object case (Payne 1980, 176), yielding $a z$ for $s$ in the so-called 'direct' case, mon for A in the so-called 'oblique' case and $\check{z}$-mon for P in the object case:

(31) Yazgulyami (East Iranian, Pamir; Bickel and Nichols 2009, 309, original sources cited therein, glossing modified)
[DIR $\rightarrow$ S]
$[\mathrm{v}]$
a. $a ́ z=\partial m \quad$ mot $\mathrm{mad}$
(intransitive)
1SG:ABS=1SG tired become:PST
'I am tired.'
$[\mathrm{OBL} \rightarrow \mathrm{A}][\mathrm{OBJ} \rightarrow \mathrm{P}][\mathrm{v}]$
b. mon š-tu wint
1SG:ERG OBJ-2SG see:PST
'I saw you.' (lit. Me saw to-you)
(transitive)

Horizontal alignment stands out in grouping $\mathrm{A}$ and $\mathrm{P}(\mathrm{S} \neq \mathrm{A}=\mathrm{P})$. It is also known as 'double oblique alignment' after the terminology for case systems in modern Iranian languages, where this pattern predominates (Payne 1980), as illustrated below for Rošani, another Pamir language. The s pronoun $(a z)$ is completely distinct from the A and P pronouns, while the latter two are the same in the so-called 'oblique' case $(\mathrm{mu})$. The A-P-V word order contributes to their role discrimination, A coming immediately before $P$.

(32) Rošani (East Iranian, Pamir; Payne 1980, 156, glossing adapted)

[ABs:ss] [v]

a. $a z=u m \quad$ tar $\check{x} \bar{a} r \quad v i j$

(intransitive)

ISG:ABS=1SG to town be:PERF

'I've been to town.'

$$
\text { [овL:A] [OвL:P] [V] }
$$

b. $\boldsymbol{m u} \quad \boldsymbol{t} \overline{\boldsymbol{a}}$ wunt

(transitive)

1SG: OBL 2SG: OBL See:PST

'I saw you.' (lit. Me saw your)

c. $t \overline{\boldsymbol{a}} \quad \boldsymbol{m u} \quad$ wunt

2SG: OBL 1SG: OBL see:PST

'You saw me.' (lit. Your saw me) 
Verbal person marking can show the same patterns. The $s$ in (32a) is also treated differently in triggering indexing via a clitic person form $(=u m)$, while A and $P$ are not indexed. ${ }^{72}$ Similarly, Comrie $(1978,342)$ explains that if only one argument function is indexed, this will be $\mathrm{s}$. The indexing is thus horizontal in terms of trigger potential and morphological marking. In yet other languages, such as Vafsi (Northwestern Iranian, Tati; Stilo 2004b, 239-240), the indexing may also be horizontal in terms of trigger potential only, since verbal person marking of A and P is largely optional, but that of $\mathrm{s}$ is obligatory.

On the whole, intransitive clauses are treated differently from transitive clauses in all of these systems. This will also be a recurring theme in the NeoAramaic dialects we will examine. Such patterns will be further discussed in the following chapters. ${ }^{73}$

\subsubsection{Syntactic Properties: Role and Reference Inversion in Neo-Aramaic}

The Neo-Aramaic languages we will examine have the following constructional split in common. Two sets of person markers are used in transitive verbal forms, but each indexes the reverse grammatical function of qațl- in the qtil-based system. qțil- and qatal- are the mirror image of each other in the majority of NENA dialects as well as Turoyo at least in some respects. The constructions based on qțil-, however, will often comprise a subsystem of their own, depending on the dialect.

The same template and person markers for qațal- can be found for qțil-. Ultimately, however, each dialect (bundle) can 'do its own thing. ${ }^{74}$ Generally speaking, nevertheless, the E-set is used to mark the patient in both Țroyo and the majority of NENA for at least the third person.

For both qatal-75 and qțil-inflectional bases, the shape and order of the 1st and 2 nd set, i.e. E- and L-suffixes, are equivalent, but their cross-referencing of the A and P function is reversed. This is obviously reminiscent of an activepassive alternation. While reminiscent of the passive, the functions of the person indexes are also inverted, which clearly rules out a passive analysis on at least a synchronic level (Doron and Khan 2012).

72 These clitics, however, also feature in the marking of A in other contexts and are extended to clauses like (19b) and (19c) among younger speakers (Payne 1980, 158-161).

73 Particularly Sections 3.4. and 4.3.

74 In fact, theoretically, each set of person forms can be used to encode the grammatical functions S, A or P. This is by no means uniform in the dialects, as Chapters 3 to 6 demonstrate.

75 Generally, however, what applies to qața- will also apply to the imperative and possibly other innovated inflectional bases, which we will leave out of discussion. 
By way of comparison, inverted morphological marking that is sensitive to tense-aspect can also be found in Kartvelian and Iranian languages. For instance Georgian, illustrated in (33) below, has several distinct case-marking patterns depending on tense (Harris 2001). The nominative case is used to mark $\mathrm{s}$ and $\mathrm{A}$ for the present or future, while the dative marks $\mathrm{A}$ in the evidential perfect. The dative case marks $P$ in the first, but the nominative marks $P$ in the latter. The result is that the case morphology refers to exactly opposite syntactic roles depending on the verbal construction.

(33) Georgian (Kartvelian, Georgia; Harris 2001, 1378-1380, glossing slightly adapted)

$\begin{array}{llll} & {[\mathrm{A}]} & {[\mathrm{P}]} & {[\mathrm{v}]} \\ \text { I: NOM-DAT } & \text { merab-i } i \quad \text { rvino-s } & \text { amoirebs } \\ & \text { Merab-NOM wine-DAT take.out } \\ & \text { 'Merab will take out wine' }\end{array}$

(future)

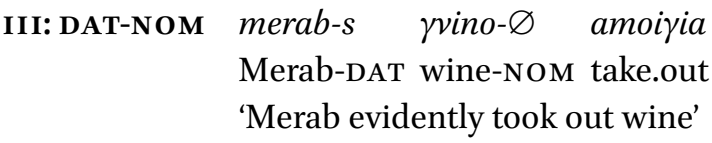

(perfect)

Similarly, a characteristic of Northwest Iranian languages is that they generally mark A in the past tense in the same way as $\mathrm{P}$ in the present tense. When this primarily involves verbal person marking, $\mathrm{P}$ in the present tense and $\mathrm{A}$ in the past tense will both be marked by the same set of enclitic person markers. Apart from the third person, the marking of the other respective roles can also be identical, as in Gorani, illustrated below. What marks $\mathrm{P}$ in the present, marks A in the past, and vice versa:

(34) Gorani (Stilo 1981, 168)
a. $m a-b a r \quad-d e \quad-m \bar{a}$
IND- see $_{\text {PRES }}-\mathrm{A}: 2 \mathrm{PL}-\mathrm{P}: 1 \mathrm{PL}$
'You ${ }_{\mathrm{PL}}$ see us.'
$\left[\begin{array}{lll}\mathrm{V} & \underline{\mathrm{P}} & -\mathrm{A}\end{array}\right]$
b. bard -ayde $-m \bar{a}$
See $_{\text {PAST }}-\mathrm{A}: 2 \mathrm{PL}-\mathrm{P}: 1 \mathrm{PL}$
'We saw you ${ }_{\mathrm{PL}}$ '


North-Eastern and Central Neo-Aramaic languages are similar in this respect. What marks $\mathrm{P}$ in the qatal-constructions typical of the imperfective present marks A in the qțil-, i.e. the preterit. The role marking can be partially or completely inverted.

\subsubsection{Inverted Role Marking in qțil-}

Two sets of person markers are used in transitive verbal forms in NENA and Turoyo, but each indexes the reverse grammatical function of qațal-in the $q t ̦ i$-based system. Transitive clauses manifest a type of what we can call role reference inversion ${ }^{76}$ conditioned by the kind of inflectional base, which may be characterized as follows. The table below can be taken as representative. While the L-series marks $\mathrm{P}$ in qațal-, it marks A in qțil-, and vice versa for the E-series. This morphological role reference inversion generally applies to their entire functional distribution.

The zero morpheme for the E-set third masculine singular leads to ambiguous forms in the perfective, cf. grəš-lan 'We pulled' and grəš- $\varnothing$-lan 'We pulled him. The context will usually make clear whether a $3 \mathrm{~ms}$. $P$ argument is meant. ${ }^{77}$

The morphemes, however, are not completely identical for both inflectional bases in all dialects. In Christian dialects of the Khabur valley going back to villages in SE Turkey (Talay 2008, 317-318) and Christian dialects of Iranian Azerbaijan (Hoberman 1989, 105-106; Khan 2016, 384) and the closely related dialect of Diyana (NW Iraq; Napiorkowska 2015, 209), the 3pl. E-set morphemes $-i$ and $-e$ differ for strong verbs depending on their usage in qațl-and qțil-before L-suffixes, i.e. 'qațl-i- 'they kill' vs. qțil-e- 'killed them'. In fact, Napiorkowska $(2015,197-198)$ indicates that some levelling has taken place between the inflection of qatal- and qțil-, so that $-e$ is now available to express $3 p l$. agents in the inflection of qațal-:

(35) C. Diyana (NW Iraq; Napiorkowska 2015, 198, 209)

a. patx-i-le $\sim$ patx-e-le 'They open $\mathrm{it}_{\mathrm{M}}$ '

b. ptix-e-le 'He opened them'

Finally, there can be considerable—dialect-dependent—-morphological overlap between qatal- and qțil-bases due to vowel reduction, which will be pointed out when relevant. Consider, for instance, final-/y/ verbs such as $x z y$

76 Or "agreement inversion" (Doron and Khan 2012). See also Polotsky (1979, 209, 1991, 266, 1994, 95), Hoberman (1989, 96, 113), Mengozzi (2002b, 44-45).

77 This is consistent with the cross-linguistic tendency that the third person is paradigmatically zero (Siewierska 2004, 24). 
TABLE 7 Conjugation of qațal-and 'perfective' with object indexes in Jewish 'Amedia

\begin{tabular}{|c|c|c|c|c|c|}
\hline $\begin{array}{l}\text { qaṭol- } \\
\mathrm{V}_{\text {IPFV }}\end{array}$ & $\begin{array}{l}\text { E-set } \\
\text { A }\end{array}$ & $\begin{array}{l}\text { L-set } \\
\text { P }\end{array}$ & $\begin{array}{l}q t \text { til- } \\
\mathrm{V}_{\mathrm{PFV}}\end{array}$ & $\begin{array}{l}\text { E-set } \\
\text { P }\end{array}$ & $\begin{array}{l}\text { L-set } \\
\text { A }\end{array}$ \\
\hline ¿garəš & $-\varnothing$ & $-l a$ & graš & $-\varnothing$ & $-l a$ \\
\hline ogarš & $-a$ & $-l e$ & griš & $-a$ & $-l e$ \\
\hline garš & $-i$ & -lan & griš & $-i$ & -lan \\
\hline 'garš & $-\partial t$ & $-t i$ & griš & $-\partial t$ & $-t i$ \\
\hline ogarš & $-a t$ & $-t i$ & griš & $-a t$ & $-t i$ \\
\hline garš & -átu & $-l u$ & griš & -átu & $-l u$ \\
\hline ogarš & $-\partial n$ & $-\operatorname{nax}$ & griš & $-\partial n$ & $-\operatorname{nax}$ \\
\hline garš & $-a n$ & $-n u x$ & griš & $-a n$ & $-n u x$ \\
\hline garš & -áx & -loxun & griš & -áx & -loxun \\
\hline
\end{tabular}

'see', which have a qțil-base and qațal-base that are only distinguishable by the vowel in the stem:
xəzy-a-le 'He saw her'
xazy-a-le 'She sees him'

Similarly in the inflection of stem III verbs, the distinction can be marginal, e.g. J. Sulemaniyya (NE Iraq; Khan 2004a, 89-9o)

$$
\begin{array}{ll}
\operatorname{mrad} x-a-l e & \text { 'He boiled it } \\
\operatorname{marad}_{\mathrm{F}} \text { - } a \text {-le } & \text { 'She boils it } \\
\mathrm{M}
\end{array}
$$

The qți-base may sometimes display a slight difference in the vowel template of sound verbs when combined with both E-suffixes and L-suffixes:

$$
\begin{aligned}
& \stackrel{\text { garš-a-le 'She pulls him' }}{\text { garš-a-le }} \quad \text { 'He pulled her' instead of griš-a-le }
\end{aligned}
$$

This so-called Aufsprengung (blasting apart, i.e. breaking up) of the syllable from griš- to giřs- $\sim$ garš- before vowels is characteristic of several Jewish NENA dialects and is also found in Christian NENA dialects in Turkey, such as C. Beșpən (Sinha 2000, 142), and varieties of Țuroyo. Also the inflectional bases may even be identical at least for some derived stems in Țuroyo and the NENA 
dialect C. Hertevin (SE Turkey; Jastrow 1988, 38), so that a form like Turoyo mhalq-i-le (stem II) can either denote the preterit 'He threw them' or subjunctive 'May they throw it $_{\mathrm{M}}$ '.

Transitive verbal constructionsthat are based on qțil- and qațl- are thus characterized by an inversion of role referencing, while the sets of person markers are morphologically the same and only the inflectional base differs. What holds for A (E-set) in qațal-will generally also hold for A (L-set) in qțil-, and vice versa for $\mathrm{P}$.

The functional distribution of the E-suffixes or L-suffixes is completely mirrored according to the role reference inversion. This can be seen, for instance, in the indexing of prominent object NPs. Coghill (2014) mentions that, as a general tendency, indexing is primarily used to differentially mark topicalized NPS and definite and specific indefinite NPS across NENA dialects. Compare qațalin (36) and qțil- in (37) for J. 'Amedia below.

(36) qațal-base (J. 'Amedia, NW Iraq; Hoberman 1989, 102-104)
a. $k$-šam' $\quad-i \quad$ baxta
IND-hear $_{\text {IPFV }}-A: 3 P L$ woman:FS
'They hear a woman.'
b. $k$-šam $\quad-i \quad$-la $\quad$ (L-set $\rightarrow$ pronominal P)
IND-hear ${ }_{\text {IPFV }} \quad-A: 3$ PL $\quad-P: 3 F S$
'They hear her.'
$\begin{array}{lllll}\text { c. } k \text {-šam } & -i & -l a & \text { baxta } & \text { (L-set indexes definite P) }\end{array}$ IND-hear $_{\text {IPFV }}-$-A:3PL $-\mathrm{P}: 3 \mathrm{FS}$ woman:FS
'They hear the woman.'

(37) qțil-base (J. 'Amedia, NW Iraq; Hoberman ibid.)
a. šme' -lu baxta
hear $_{\mathrm{PFV}}$-A:3PL woman:FS
(no indexing of $\mathrm{P}$ )
'They heard a woman.' (lit. Them heard woman)
b. $\check{s} m i ’ \quad-a \quad-l u$
hear $_{\mathrm{PFV}}-\mathrm{P}: 3 \mathrm{FS} \quad-\mathrm{A}: 3 \mathrm{PL}$
'They heard her.' (lit. Them heard she)

$($ E-set $\rightarrow$ pronominal $\mathrm{P})$
$\begin{array}{lllll}\text { c. } s \text { mi } & -\boldsymbol{a} & -l u \quad \text { baxta } & \text { (E-set indexes definite P) }\end{array}$ hear $_{\mathrm{PFV}}$-P:3FS -A:3PL woman:FS
'They heard the woman.' (lit. Them heard she, the woman)


The L-suffix cross-references for qațal in $(36 \mathrm{a}-\mathrm{c})$ what the E-suffix crossreferences for qtil- in (37a-c), and vice versa. Depending on the base, the L-set or E-set marks P.

Ditransitive verbs can mark the object in the same way. When the role marked by the E-set is a recipient in the qțil-forms, it can also similarly be marked by the L-set in the corresponding qațal-forms, for example the addressee of ' $m r$ 'say':

(38) J. 'Amedia (NW Iraq; Greenblatt 336.8)

a. g-amr -әn -nux

(qațal-)

IND-Say $_{\text {IPFV }} \quad-A: 1 M S \quad-R: 2 M S$

' $\mathrm{I}_{\mathrm{M}}$ tell you $_{\mathrm{Ms}}$ ',

b. mir -at $-t i$

say $_{\mathrm{PFV}^{-}}$R:1MS -A:2MS

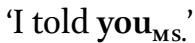

The same holds for the theme. Where the E-set marks the theme and/or crossindexes a definite full nominal theme for qțil-, the L-set does so for the corresponding qatal-forms. This is illustrated below for the ditransitive verb 'give' and the theme pare 'money', a plurale tantum.

(39) J. 'Amedia (NW Iraq; Hoberman 1989, 107-109)

$\left[\begin{array}{lll}\mathrm{V} & -\mathrm{A} & -\mathrm{T}\end{array}\right] \quad[\mathrm{DAT} \rightarrow \mathrm{R}]$

a. g-yawal $\quad-\varnothing \quad-l u \quad t a l-i$

(qațal-)

FUT-give ${ }_{\text {IPFV }}-A: 3 M S$-T:3PL to-me

'He gives it (lit. them, i.e. the money) to me.'

$[\mathrm{V}: \quad-\mathrm{A} \quad-\mathrm{T}] \quad[\mathrm{T}] \quad[\mathrm{DAT} \rightarrow \mathrm{R}]$

b. g-yawal $\quad \varnothing \quad$-lu pare țal-i (qațal-)

IN D-give $_{\text {IPFV }}$-A:3MS -T:3PL money:PL to-me

'He gives the money to me.'

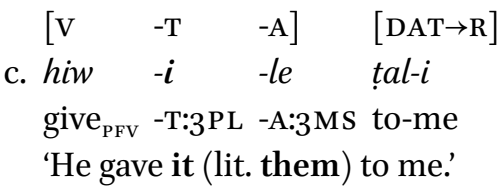



$\left[\begin{array}{lll}\mathrm{V} & -\mathrm{T} & -\mathrm{A}\end{array}\right] \quad[\mathrm{T}] \quad[\mathrm{DAT} \rightarrow \mathrm{R}]$
d. hiw $-i \quad-l e$ pare tal-i
give $_{\mathrm{PFV}}-\mathrm{T}: 3 \mathrm{PL}-\mathrm{A}: 3 \mathrm{MS}$ money:PL to-me
'He gave the money to me.'

Finally, the differential object marker, if it is used in a dialect for qațl-, can also be used in corresponding qtil-based clauses, for example:

(40) J. Sanandaj (W Iran; Khan 20o9, 158, 221)

$[\mathrm{DOM} \rightarrow \mathrm{P}] \quad[\mathrm{V}-\mathrm{A}]$

a. hal-d-o gora garəš- $\varnothing$

(qațl-)

DOM-LK-DEM:SG man:MS pull ${ }_{\mathrm{IPFV}}-\mathrm{A}: 3 \mathrm{MS}$

$(q t$ til-)

'He pulls that man.'
$[\mathrm{DOM} \rightarrow \mathrm{P}]$
b. hal-d-o
gora $\quad \begin{aligned} & \text { groš-le } \\ & \text { gra }\end{aligned}$
DOM-LK-DEM:Ms man:Ms pull ${ }_{\text {IPFV }}$-A:3MS
'He pulled that man.'

Across the constructional split between qatal- and qțil-, therefore, the functions of $\mathrm{A}$ and $\mathrm{P}$ are uniform in the aforementioned respects in the majority of Neo-Aramaic languages. The fact that verbal person marking of A, like s, is not triggered by argument properties such as definiteness sets it apart from other grammatical functions, i.e. $\mathrm{P}, \mathrm{T}$, possibly R. Indexing or prepositional marking of the object nominals is always conditioned by such argument properties. The conditioning and trigger potential of arguments is therefore the same throughout the verbal system. This is one relevant piece of evidence for consider the constructional split between qațal- and qtil- not to be one of active-passive (Doron and Khan 2012). Further supporting evidence can be found in the syntactic behavioral properties.

\subsubsection{Syntactic Behavioral Properties}

Syntactic behavioral properties include the control of reflexives, relativization, interclausal co-referential reduction (sometimes called equi NP-deletion) and same subject constraints in complement clauses such as the complement of modal verbs like 'can', 'want', 'begin', 'finish' etc. ${ }^{78}$ Such syntactic behavioral properties tend to be confined to particular grammatical functions.

\footnotetext{
78 See for example Keenan (1976), Silverstein (1976) and Dixon (1979, 1994).
} 
Take for instance the anaphoric deletion of an equivalent NP across clausal chains. If applicable in the language, this is also manifested in the control of verbal agreement of connected verbs across clauses. The cross-clausal coreference of $\mathrm{s}$ and $\mathrm{A}$ is the same in accusative syntax. A typical example in English is offered in (41) below, taken from Comrie (1988), where s and A control anaphoric deletion and P does not. Equivalent NP co-reference in complement clauses or conjunctions is the same for $\mathrm{S}$ and $\mathrm{A}$, but distinct from $\mathrm{P}$ in accusative syntax. A particular device may be available to signal a switch of reference, for example, independent pronominalization or a full $\mathrm{NP}$, and indicates that the referents are distinct. If the controller of the anaphoric deletion were distinct in the conjoined intransitive clauses, English would highlight this by expressing the subject as an independent pronoun or full NP, i.e. The man hit the woman and she/the woman ran away.

$[\mathrm{s}]$ (41)
a. The $\operatorname{man}_{\mathrm{i}}$ came and ...
[A]
$[\mathrm{P}]$
$\left[\varnothing_{\mathrm{i}}\right]$ ran away.
$[\mathrm{S}=\mathrm{A} \neq \mathrm{P}]$
b. The $\operatorname{man}_{\mathrm{i}}$ hit the woman $\mathrm{y}$ and $\ldots .\left[\varnothing_{\mathrm{i} / *_{\mathrm{y}}}\right]$ ran away.

$[\mathrm{s}=\mathrm{s}]$

A morphologically ergative construction generally patterns according to accusative syntactic behavior. In a strictly morphological ergative pattern, then, the ergative A fulfills the syntactic behavior that corresponds to the $s$ of intransitive constructions like the nominative $(\mathrm{S}=\mathrm{A})$ in an accusative system. This also holds for the Neo-Aramaic dialects with ergative alignment (Doron and Khan 2012). A marked by the L-suffixes, for instance, controls reflexives in the same way as $s$ in qațal-based constructions. An example is given below for Țuroyo.

(42) Turoyo (Rural, SE Turkey)

a. ú-z'uro ko-hoze $\varnothing \quad$ ruh-e

the-boy:MS IND-See ${ }_{\text {IPFV }}$-A:3MS REFL-3MS

'The boy sees himself.' (Miden, Ritter 1967-1971, 75/149)

b. ftih -i -le haze -le ruḥ-e

open $_{\mathrm{PFV}}-\mathrm{P}: 3 \mathrm{PL}-\mathrm{A}: 3 \mathrm{MS}$ see $_{\mathrm{PFV}}$-A:3MS REFL-3MS

'He opened them (i.e. his eyes) (and) found himself (in his father's castle).' (Miden, ibid. 74/457)

Independent pronouns are not at all required to indicate a switch of topic reference in Neo-Aramaic. In (42c) below, for example, P nominal id $-e$ 'his hand' is continued as $s$ in the subsequent verbal construction without any need to indi- 
cate the switch reference. As co-nominals are not obligatory (unlike in English), the verbal person marking is sufficient.
c. hano graš $\quad$ le $i \underline{d}-e \quad u$ nafiq $-o$
DEM:MS open ${ }_{\mathrm{PFV}}-\mathrm{A}: 3 \mathrm{MS}$ hand:FS-his and go.out $_{\mathrm{PFV}}-\mathrm{S}: 3 \mathrm{FS}$
'He pulled his hand and $\mathrm{it}_{\mathrm{F}}$ got out.' (ibid. $46 / 17$, 'Iwardo)

Finally, it is rare but possible for ergative alignment to be found not only in morphology, but also in syntactic behavior, so that it is $\mathrm{S}$ and $\mathrm{P}$ that share more syntactic behavioral properties than A, much like the patient in the passive. ${ }^{79}$

Dyirbal is an oft-cited example of this, where the behavioral properties of $\mathrm{P}$ and s share the same pattern. As illustrated in (43) below, it is P that controls anaphoric deletion rather than A. If A were intended to control the anaphoric deletion, Dyirbal would require an antipassive construction to indicate such a switch, where the agent is expressed as S (Comrie 1988, 11).

(43) Dyirbal (Australia, North Queensland; Comrie 1988, 10, glossing slightly simplified)

\begin{tabular}{|c|c|c|}
\hline 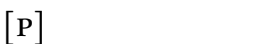 & {$[\mathrm{S}=\mathrm{P} \neq \mathrm{A}]$} & \\
\hline $\begin{array}{l}\text { Balan dy }^{y} \text { ugumbil } \\
\text { woman-ABS }\end{array}$ & $\begin{array}{ll}\text { baygulyaraggu } & \text { balgan } \\
\text { man-ERG } & \text { hit }\end{array}$ & $\begin{array}{l}\text { baninyu } \\
\text { came }\end{array}$ \\
\hline
\end{tabular}

The s-like behavioral properties, such as equi-NP deletion of $\mathrm{P}$ in languages like Dyirbal, are very passive-like. They are, however, irrelevant to languages where ergativity is only manifested in morphological properties and not syntactic behavior. ${ }^{80}$

The same syntactic behavior follows an accusative pattern throughout all of Neo-Aramaic. ${ }^{81}$ It is only the morphological marking that shows different alignment types.

\subsubsection{The Semi-Clitic Nature of the L-set}

The L-series have some morphological peculiarities reminiscent of clitics in comparison to the E-series (Doron and Khan 2012, 228). They may be omitted or stacked on verbal forms in certain dialects.

79 See Subsection 4.2. on the relationship between the passive and ergative.

8o See Keenan and Comrie (1977), Comrie (1988, 12-15), Givón (1995, 256-267).

81 See also Coghill $\left(2016,73^{-81}\right)$ for inconclusive tests of syntactic ergativity in NENA. 
First of all, the L-suffixes are different in that they can be duplicated on a verb, depending on the dialect. (44a) below offers an example of such stacking of L-suffixes in a qațal-based construction. The first L-set marks the theme, the second L-set marks the recipient.

(44) J. Dohok (NW Iraq)

a. $b-y \bar{a} w \quad-\partial ́ n \quad-n \boldsymbol{a} \quad-l o x$

FUT-give $_{\text {IPFV }}$-A:1MS -T:3FS -R:2MS

' $\mathrm{I}_{\mathrm{M}}$ will give her (i.e. my daughter) to $\mathrm{you}_{\mathrm{MS}}$ '.

Stacking may also occur in qțil-. In (44b) below, the first L-set denotes the agent, the second one the recipient.

b. húl -li $\quad$-la zuze

give $_{\mathrm{PFV}}-\mathrm{A}: 1 \mathrm{SG}-\mathrm{R}: 3 \mathrm{FS}$ money:PL

'I gave her money'.

In both constructions, the extra L-suffix on top of the other is limited to the $\mathrm{R}$ role. ${ }^{82}$ Thus it is not possible to say **hú-li-la talox 'I gave her to you', as the additional L-suffix is not available to express the theme, nor the patient such as **gráś-li-la 'I pulled her' (Hoberman 1989, 108-109).

The L-suffixes enjoy an overall semi-mobile status, unlike other suffixal person markers. This is a lingering feature of their enclitic origin (Doron and Khan 2012, 231) and sets them apart from other verbal affixes. L-suffixes allow elements to intervene between the verbal base and its agreement, which also includes the E-suffixes and the past convertor -wa-. Examples (45)-(46) offer a comparison.

(45) 'ogarš-at-ti 'You ${ }_{\mathrm{FS}}$ pull me.'

'garš-át-wa-li 'You ${ }_{\mathrm{Fs}}$ would pull me.'

(46) griš-at-ti 'I pulled you ${ }_{\mathrm{Fs}}$ '

griš-át-wa-li 'I had pulled you $\mathrm{Fs}_{\mathrm{FS}}$ '

82 Additional L-suffixes, however, are generalized for all objects in a few Christian dialects in the western periphery in SE Turkey and Jewish dialects in NW Iran; see $§ 4 \cdot 4 \cdot 3$. 
In addition, the L-suffixes marking $P$ in qatal- may be omitted, creating a morphologically objectless construction (for whatever purpose). This also applies to the E-suffixes that express P in qțil-. Compare:

(47) $k$-axl-a 'She is eating.'

(48) xal-la 'She ate.' (implicit patient)

(implicit patient)

Yet unlike E-suffixes in qațal-, the L-suffixes can also be omitted in qțil-based constructions in some NENA dialects. The patient remains expressed by the Esuffixes and the construction becomes agentless:

(49) xil-a ' $\mathrm{It}_{\mathrm{F}}$ was eaten (by sb.).' xil-a-wa ' $\mathrm{It}_{\mathrm{F}}$ had been eaten (by sb.).'

(implicit agent)

The L-suffixes expressing the patient in qațal- behave thus in a similar fashion to the L-suffixes expressing the agent in qțil-. The argument they denote, the patient or agent, is left unexpressed.

And yet, while the qțil-based constructions generally show an inversion in verbal person marking that is consistent with the equivalent qațl-constructions, the agentless qtil-forms in (49) have a special status, the function of which depends on the dialect. In general, when the full agent NP is unexpressed but still manifested in agreement, this is indistinct from a situation where the co-nominal is not obligatory (Comrie 1988, 18), so that constructions like 'aya 'axl- $a$ vs. 'axl- $a$ 'She eats' are essentially not distinct from each other. Similarly, qțil-based constructions do not require a co-nominal so that 'aya ${ }^{\circ} x a l-l a$ vs. ${ }^{\circ} x a l-l a$ 'She ate' are essentially non-distinct. Nevertheless, qațal-forms cannot leave the agent unexpressed in both verbal person marking as well as nominal marking. The qțil-based constructions are strikingly different in that they may do so. Moreover, it is ambiguous as to whether such forms are passive, i.e. intransitive, or ergative, i.e. transitive. The omission of A can still yield wellformed sentences in languages that otherwise exhibit an ergative pattern. ${ }^{83}$ Both morphological and syntactic behavioral properties will play a key role in assessing their passive-like or ergative-like properties. As the dialects differ in this respect, we will discuss this for each dialect group in the following chapters. $^{84}$

83 Cf. Keenan $(1976,313)$ and Comrie $(1988,18-19)$.

84 Particularly Section 3.5. for Trans-Zab Jewish NENA dialects, Section 4.2. for other NENA varieties and Subsection 5.2.3.2. for Țuroyo. 
In terms of verbal morphology, then, the L-set can be omitted and even added to another instance thereof, stacking the L-suffixes. Even as agent markers they can also be omitted in the inflection of qtil-. Other sets of person markers, such as the E-set, do not have these properties. All of this is an epiphenomenon of the L-suffixes, being historically cliticized prepositional person markers.

\subsection{Conclusion: A Construction-Specific Approach}

The variation of alignment in Neo-Aramaic is inextricably bound to the life cycle' of a specific combination of a particular inflectional base (qțil-) going back to a verbal adjective as well as a particular set of person markers and the preposition $l$ - This alignment variation is determined by the properties of constructions that instantiate argument groupings and not per se of a language as a whole (Comrie 1989, 114).$^{85}$ Indeed, we already noted that qțil-based constructions can have a special status. Such a typological approach thus diverges from other approaches to Neo-Aramaic alignment (e.g. Doron and Khan 2012; Kalin and van Urk 2015) where constructions are not always regarded as meaningful units in themselves, but as having meaning derived from the lexical parts of speech inserted in a system of rules blind to the observable output. Morphology is viewed only as a surface phenomenon and discoveries about universal (innate) principles of language are the ultimate goal. This notwithstanding, morphological marking is crucial for the purposes of this study in order to capture the microvariation typologically. Constructions themselves are viewed as integrated wholes and independent units of grammatical meaning, without a deeper hidden structure or indeed more basic alignment type of the language in its entirety.

This has important repercussions to bear in mind before examining the Neo-Aramaic microvariation in closer detail. First of all, when we consider that alignment typology identifies a (cor)relation between the properties of arguments across intransitive and transitive constructions, we must take into account that ergativity as an alignment type is not a property of one particular transitive construction. There is nothing inherently ergative about the qtal-le verbal forms in Neo-Aramaic, even though this is often taken for granted in the literature. ${ }^{86}$ We establish ergativity on the basis of the shared, distinctive prop-

85 Cf. Croft (2001, 168), Haig (2008).

86 See further Chapter 4 for a detailed discussion of this issue. 
erties of $\mathrm{S}$ and $\mathrm{P}$ in contradistinction to $\mathrm{A}$. If $\mathrm{S}$ and $\mathrm{P}$ are not grouped in this sense, it makes no sense to speak of ergativity.

Secondly, an alignment type such as ergativity can be identified from different perspectives without being an essential part of either the constructions or the language as a whole. Verbal person marking in itself is a complex phenomenon that may not show a uniform treatment of grammatical functions on every level of abstraction. This concerns the trigger potential, conditionality, morphological marking and affix order. Which property is a more basic characterization of verbal person marking alignment than another is a moot point. Since the trigger potential and conditionality as manifested in differential object marking is largely uniform across Aramaic languages, it is the morphological marking that will be considered to be key here for comparative purposes, without assuming that there is a deeper overarching alignment.

Lastly, intransitive and transitive constructions can vary and evolve independently of each other. Certain alignment types such as the tripartite $(\mathrm{A}=\mathrm{S}=\mathrm{P})$ and horizontal $(\mathrm{S} \neq \mathrm{A}=\mathrm{P})$ ones do not group $\mathrm{S}$ with any other argument, thus not showing any particular relation between the coding of arguments across intransitive and transitive constructions. Speakers can adjust or expand the usage and reshape the architecture of intransitive and transitive constructions independently of each other as well as the alignment as a whole. Each construction thus has the full potential to 'lead a life of its own' within the Neo-Aramaic speech community.

\subsection{Overviews of Inflection}

TABLE 8 Basic pronominal inventory in Țuroyo

\begin{tabular}{|c|c|c|c|c|c|}
\hline \multirow[b]{3}{*}{$\begin{array}{l}1 \mathrm{MS} \\
\mathrm{FS} \\
\mathrm{PL}\end{array}$} & \multirow{3}{*}{$\begin{array}{l}\text { Independent } \\
\text { ono, ŭno } \\
\text { aḥna, əḥna }\end{array}$} & \multicolumn{4}{|c|}{ Dependent } \\
\hline & & \multicolumn{2}{|c|}{$\begin{array}{c}\text { Basic copula } \\
\text { (enclitic) }\end{array}$} & \multicolumn{2}{|c|}{$\begin{array}{l}\text { Adnominal } \\
\text { (possessive) }\end{array}$} \\
\hline & & $\begin{array}{l}\text { z'úro-no } \\
\text { z'úrto-no } \\
\text { z'úre-na }\end{array}$ & $\begin{array}{l}\text { 'I } \mathrm{I}_{\mathrm{M}} \text { am small' } \\
\text { 'I } \mathrm{F}_{\mathrm{F}} \text { am small' } \\
\text { 'We are small' }\end{array}$ & $\begin{array}{l}b a b-i \\
b a b-a n\end{array}$ & $\begin{array}{l}\text { 'my father' } \\
\text { 'our father' }\end{array}$ \\
\hline $\begin{array}{l}2 \mathrm{MS} \\
\text { FS } \\
\text { PL }\end{array}$ & $\begin{array}{l}\text { hat, hate } \\
\text { hat, hate } \\
\text { hatu }\end{array}$ & $\begin{array}{l}\text { z'úro-hat, - } \\
\text { z'úrto-hat } \\
\text { z'úre-hatu }\end{array}$ & etc. & $\begin{array}{l}b a b-\breve{u} x \\
b a b-a x \\
b a b-a y-x\end{array}$ & etc. \\
\hline
\end{tabular}


TABLE 8 Basic pronominal inventory in Țuroyo (cont.)

\begin{tabular}{|c|c|c|c|}
\hline & \multirow[t]{2}{*}{ Independent } & \multicolumn{2}{|c|}{ Dependent } \\
\hline & & $\begin{array}{c}\text { Basic copula } \\
\text { (enclitic) }\end{array}$ & $\begin{array}{l}\text { Adnominal } \\
\text { (possessive) }\end{array}$ \\
\hline $3 \mathrm{MS}$ & hiye, huwe & z'úro-yo & $b a b-e$ \\
\hline FS & hiya & $z \stackrel{\text { úrto-yo }}{ }$ & $b a b-a$ \\
\hline PL & hanne, -nәk & z'úre-ne & $b a b-a y-y e$ \\
\hline
\end{tabular}

DATA BASED ON RITTER (1990)

TABLE 9 Basic pronominal inventory in J. 'Amedia

\begin{tabular}{|c|c|c|c|}
\hline \multirow[b]{3}{*}{$\begin{array}{l}1 \mathrm{MS} \\
\text { FS } \\
\mathrm{PL}\end{array}$} & \multirow{3}{*}{$\begin{array}{l}\text { Independent } \\
\text { 'ana } \\
\text { 'ăxəni }\end{array}$} & \multicolumn{2}{|c|}{ Dependent } \\
\hline & & $\begin{array}{c}\text { Basic copula } \\
\text { (mostly enclitic) }\end{array}$ & $\begin{array}{l}\text { Adnominal } \\
\text { (possessive) }\end{array}$ \\
\hline & & $\begin{array}{ll}\text { z'ór-ewan } & \text { 'I } \mathrm{I}_{\mathrm{M}} \text { am small' } \\
\text { z'úrt-ewan } & \text { 'I } \mathrm{I}_{\mathrm{F}} \text { am small' } \\
\text { z'ór-ewax } & \text { 'We are small' }\end{array}$ & $\begin{array}{ll}b a b-i & \text { 'my father' } \\
b a b \text {-an } & \text { 'our father' }\end{array}$ \\
\hline $\begin{array}{l}2 \mathrm{MS} \\
\mathrm{FS} \\
\mathrm{PL}\end{array}$ & $\begin{array}{l}\text { 'ahi } \\
\text { 'ahi } \\
\text { 'axtun }\end{array}$ & $\begin{array}{l}\text { z'ór-ewat etc. } \\
\text { z'úrt-ewat } \\
\text { z'ór-etun }\end{array}$ & $\begin{array}{l}b a b-u x \quad \text { etc. } \\
b a b-a x \\
\text { bab-oxun }\end{array}$ \\
\hline $\begin{array}{l}3 \mathrm{MS} \\
\text { FS } \\
\text { PL }\end{array}$ & $\begin{array}{l}\text { 'awa } \\
\text { 'aya } \\
\text { 'ani }\end{array}$ & $\begin{array}{l}\text { z'ór-ele } \\
\text { z'úrt-ela } \\
\text { z'ór-elu }\end{array}$ & $\begin{array}{l}\text { bab-e } \\
\text { bab-a } \\
\text { bab-u, -ohun }\end{array}$ \\
\hline
\end{tabular}

DATA BASED ON GREENBLATT (2O11) 
TABLE 10 Simplified overview of the main forms of the verb in NENA

\begin{tabular}{|c|c|c|c|c|c|c|c|c|}
\hline & & & Sound & & First-" & Second-y & Second-w & Final-Y \\
\hline & & $\begin{array}{l}\text { I qt! } \\
\text { 'kill' }\end{array}$ & $\begin{array}{l}\text { II } \check{s} d r \\
\text { 'send' }\end{array}$ & $\begin{array}{l}\text { II I qtl } \\
\text { 'have sb. } \\
\text { killed' }\end{array}$ & $\begin{array}{l}\text { I 'xl } \\
\text { 'eat' }\end{array}$ & $\begin{array}{l}\text { I qym } \\
\text { 'rise' }\end{array}$ & $\begin{array}{l}\text { I lwš } \\
\text { 'wear' }\end{array}$ & $\begin{array}{l}\text { I } x z y \\
\text { 'see' }\end{array}$ \\
\hline INFINITIVE & & qtala & (m)šadore & maqțole & 'ixala & qyama & lwaša & xzaya \\
\hline RESULTATIVE & FS & qtalta & $(m) s ̌ u d a r t a$ & muqtalta & xalta & qamta & lušta & xzita \\
\hline PARTICIPLE & MS & qțila & (m)šudra & muqțla & xila & qima & lwiša & хәzуа \\
\hline PERFECTIVE & $\begin{array}{l}\text { PL } \\
\text { FS } \\
\text { MS }\end{array}$ & $\begin{array}{l}\text { qțili- } \\
\text { qtila- } \\
\text { qțal- }\end{array}$ & $\begin{array}{l}\text { (m)šudri- } \\
\text { (m)šudra- } \\
\text { (m)šodar- }\end{array}$ & $\begin{array}{l}\text { muqțli- } \\
\text { muqțla- } \\
\text { muqțal- }\end{array}$ & $\begin{array}{l}\text { xili- } \\
\text { xila- } \\
\text { xal- }\end{array}$ & $\begin{array}{l}\text { qimi- } \\
\text { qima- } \\
\text { qam- }\end{array}$ & $\begin{array}{l}\text { lwiši- } \\
\text { lwiša- } \\
\text { luš- }\end{array}$ & $\begin{array}{l}x z e(n i)-/ x ә z y i- \\
x ә z y a- \\
x z e^{-}\end{array}$ \\
\hline IMPERFECTIVE & $\begin{array}{l}-\mathbf{V} \\
-\mathrm{C} \#\end{array}$ & $\begin{array}{l}\text { qațl- } \\
\text { qațal- }\end{array}$ & $\begin{array}{l}(m) s ̌ a d r- \\
(m) s ̌ a d a r-\end{array}$ & $\begin{array}{l}\text { maqț- } \\
\text { maqțal- }\end{array}$ & $\begin{array}{l}\text { 'axl- } \\
\text { 'axal- }\end{array}$ & $\begin{array}{l}\text { qem- } \\
\text { qem- }\end{array}$ & $\begin{array}{l}\text { loš- } \\
\text { lawaš- }\end{array}$ & $\begin{array}{l}x a z y- \\
x a z e-/ x a z-\end{array}$ \\
\hline IMPERATIVE & & $q t u l$ & $(m) s ̌ a ́ d a r$ & máqțal & $x u l$ & $q u$ & lwuš & $x z i / x z a w$ \\
\hline
\end{tabular}

TABLE 11 Simplified overview of qațal-conjugations in Eastern Neo-Aramaic

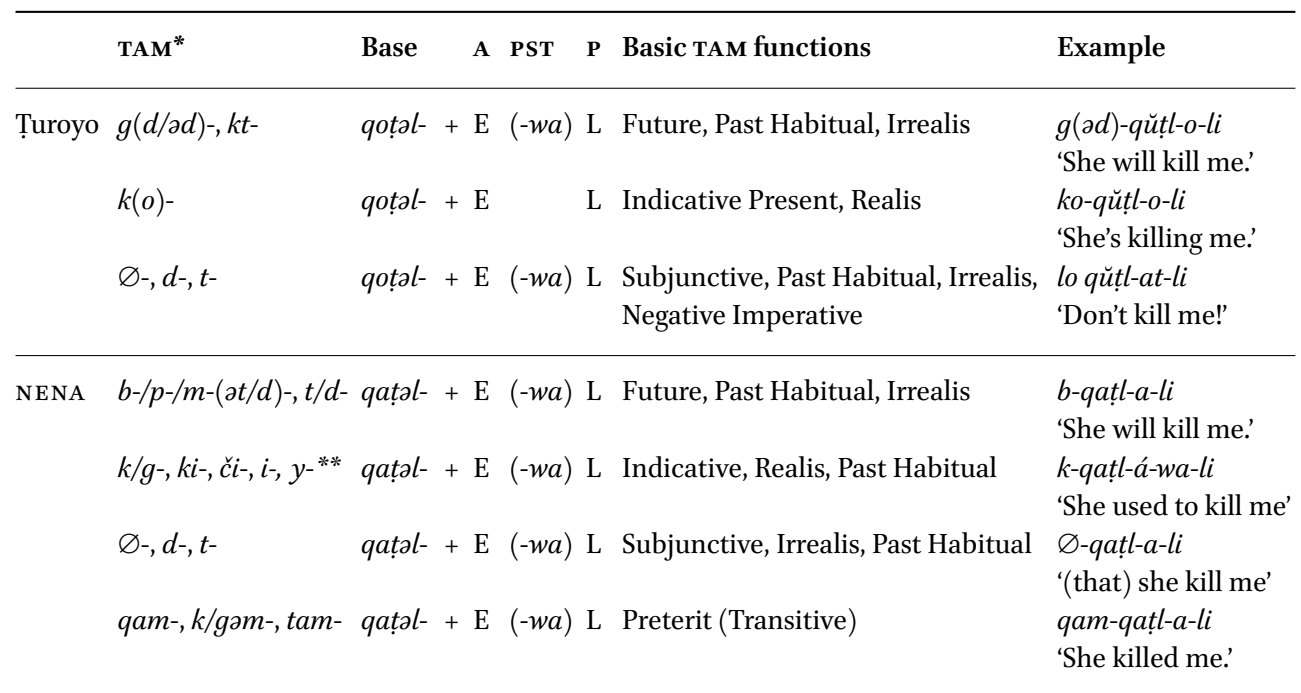

Notes: Forms given for stem I. ${ }^{*}$ TAM-markers are highly diverse and dialect-dependent in NENA (Khan 2007d). ** These may be restricted to initial weak verbs, as in C. Tyari (NENA) and Mlahsó, or absent. 